\title{
Trace Code Validation for BWR Spray Cooling Injection and CCFL Condition Based on GÖTA Facility Experiments
}

\author{
Stefano $\operatorname{Racca}^{1}$ and Tomasz Kozlowski² \\ ${ }^{1}$ San Piero a Grado Nuclear Research Group (GRNSPG), University of Pisa, Pisa 56100, Italy \\ ${ }^{2}$ Division of Nuclear Power Safety, Royal Institute of Technology, 10044 Stockholm, Sweden
}

Correspondence should be addressed to Stefano Racca, stefano.racca@dimnp.unipi.it

Received 10 March 2011; Accepted 22 June 2011

Academic Editor: Alessandro Del Nevo

Copyright (C) 2012 S. Racca and T. Kozlowski. This is an open access article distributed under the Creative Commons Attribution License, which permits unrestricted use, distribution, and reproduction in any medium, provided the original work is properly cited.

\begin{abstract}
Best estimate codes have been used in the past thirty years for the design, licensing, and safety of NPP. Nevertheless, large efforts are necessary for the qualification and the assessment of such codes. The aim of this work is to study the main phenomena involved in the emergency spray cooling injection in a Swedish-designed BWR. For this purpose, data from the Swedish separate effect test facility GÖTA have been simulated using TRACE version 5.0 Patch 2. Furthermore, uncertainty calculations have been performed with the propagation of input errors method, and the identification of the input parameters that mostly influence the peak cladding temperature has been performed.
\end{abstract}

\section{Introduction}

The development of thermal-hydraulic system codes (THSCs) began between the sixties and the seventies when conservative approaches have been used to demonstrate the safety margins necessary for the licensing and operation of a nuclear power plant (NPP). During these years, the improvements in computer technology and in computational methods have led to a new generation of THSC that can provide more realistic results without the need for conservative assumptions.

Nevertheless, the results of these advanced system codes are still affected by several kinds of uncertainties derived from many sources, for example, the modelling of the facility, the nonperfect understanding of some thermal-hydraulic phenomena, the approximation in numerical solution, the nodalization effect, and so on [1].

Therefore, it is necessary to perform a series of procedures for the code validation, using data deriving from integral test facility (ITF) or separate effect tests facility (SETF). Moreover, many methods for the evaluation of uncertainties have been developed in order to evaluate the reliability of any thermal-hydraulic code calculations, taking into account the possible sources of errors [1].
The aim of this work consists of validation of the U.S. NRC code TRACE for the spray cooling injection in a BWR reactor. The data from the Swedish GÖTA separate effect test facility are used and compared with the results derived from the modelling of the facility with the code. The study of the countercurrent flow limiting (CCFL) phenomenon and how it is modelled in the code is analysed with particular attention.

Furthermore, the propagation of input errors (PIEs) method is used to perform an uncertainty analysis on the code, and to identify which input parameters have the strongest influence on the figure of merit (peak cladding temperature).

\section{Description of the Facility}

The GÖTA test facility was located at the Studsvik Thermal Engineering Laboratory during the 70s. From 1975 to 1977, this facility was used to investigate the thermal hydraulics of typical ASEA-ATOM $8 \times 8$ BWR fuel bundles subjected to spray cooling from the top and reflooding from the bottom.

The layout of the test loop is schematically described in Figure 1. It consists mainly of two pressure vessels: a test vessel (left side of the figure) and a pressurizer (right side of 


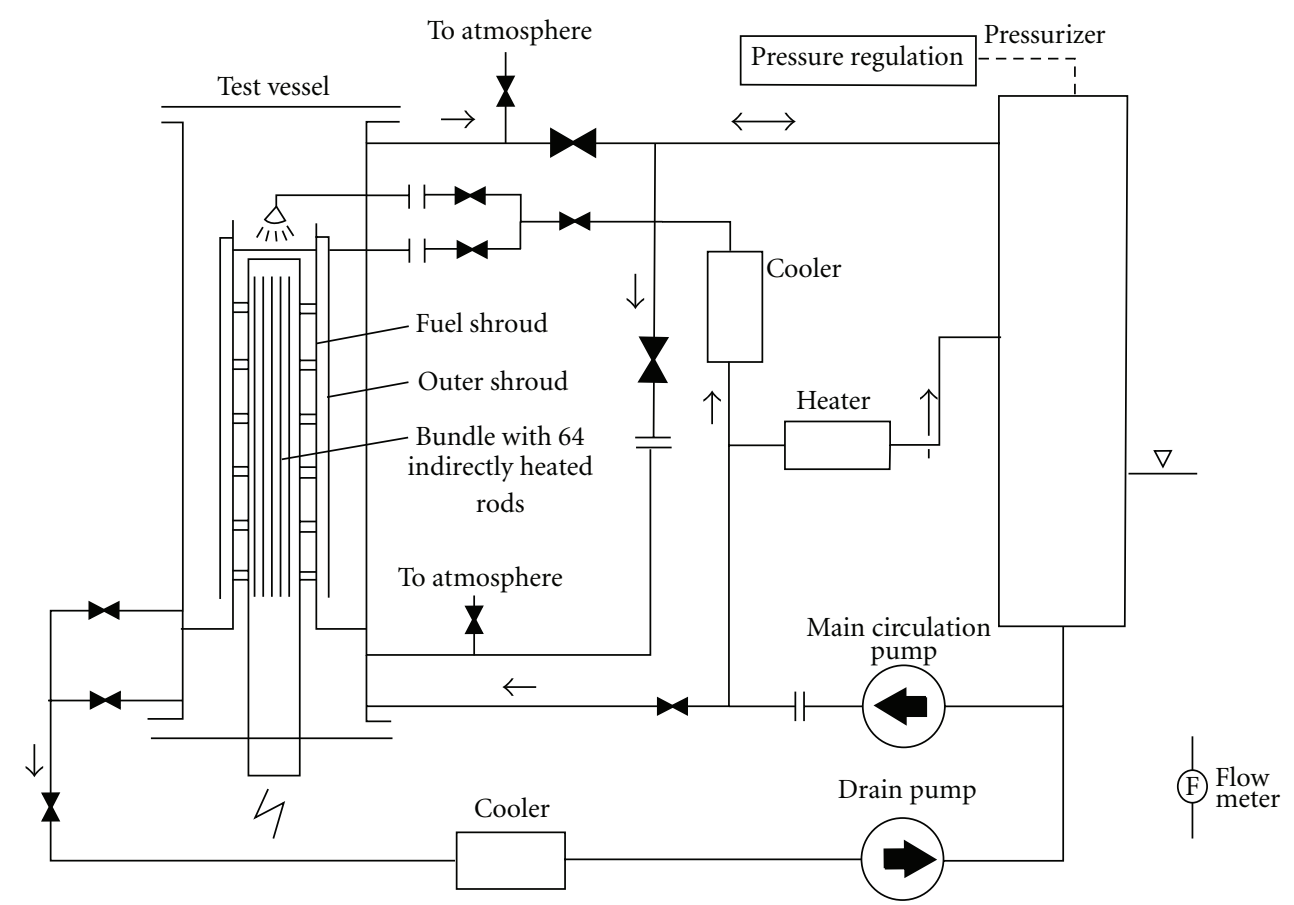

FIgure 1: The GÖTA test loop.

the figure), which also form a water reservoir for the spray system in the loop.

The pressure was regulated by the injection of subcooled water into the steam present in the upper part of the pressurizer. The steam produced in the electrically heated evaporator was used to raise the pressure in the pressurizer.

The main circulation pump drove the water from the pressurizer vessel to a water cooler, which regulated the temperature of the water, and then to the spray injection systems in the test vessel. Before being injected, the water passed through two separate mass flow measuring devices, one for each spray system. One of the two spray systems injected water through a nozzle into the fuel bundle, while a spray ring delivered water equally to all the four sides of the square bypass channel.

The temperature of water was regulated by varying the water flow on the secondary line of the water cooler. However, any variation of the secondary flow affects the performance of the cooler, so it was quite difficult, in practice, to perform the experiments with the exact prescribed water temperature.

The water collected in the lower plenum below the bundle and the water outside the bundle canister was drained back directly to the pressurizer by two separate lines that operated automatically and independently.

The pressure regulation system was not used for experiments at atmospheric pressure. In these tests, steam produced was vented directly to the atmosphere. This significantly simplified the experimental procedure. The entire test loop has been design for a maximum pressure of $7 \mathrm{MPa}$, but most of the experiments have been conducted at atmospheric pressure [2].
In this paper, only the test bundle has been modelled and simulated with the TRACE code, and no attempt has been made to model the pressurizer and the other components of the loop. The system pressure and the water temperature in the spray lines have been set as the boundary conditions for the bundle.

2.1. The Test Bundle. The test bundle is located in the test vessel. It consists of 64 rods assembly positioned by spacers in a bundle channel (inner shroud or canister). The lower, nonheated part of the rods is extended out of the channel to a bottom flange where they are fixed. Forty rods have 5 thermocouples each, mounted on the inner side of the rod cladding.

The bundle channel is mounted "leak proof" in a flange in the pressure vessel. The flange separates the upper and the lower plenum; the water falling outside to the bundle is collected in the upper plenum, while the water moving down through the channel arrives in the lower plenum of the vessel. Two schemes of the test bundle are reported in Figure 2 in order to show the characteristic dimensions of the components and their position inside the test vessel.

Outside the bundle, there is an outer channel (Figure 2(e)) that simulates the bypass region in the reactor. The outer channel is also mounted on the flange that divides the lower and the upper core, but there are openings that allow the passage of water from the gap between the inner and the outer shroud to the remaining part of the upper plenum.

The bypass channel is cooled by the spray ring (Figure 2(a)) on the top of the vessel, and it is maintained in its position by 8 space supports mounted $100 \mathrm{~mm}$ below the bundle midplane (Figure 2(b)). The spray ring tube has 92 


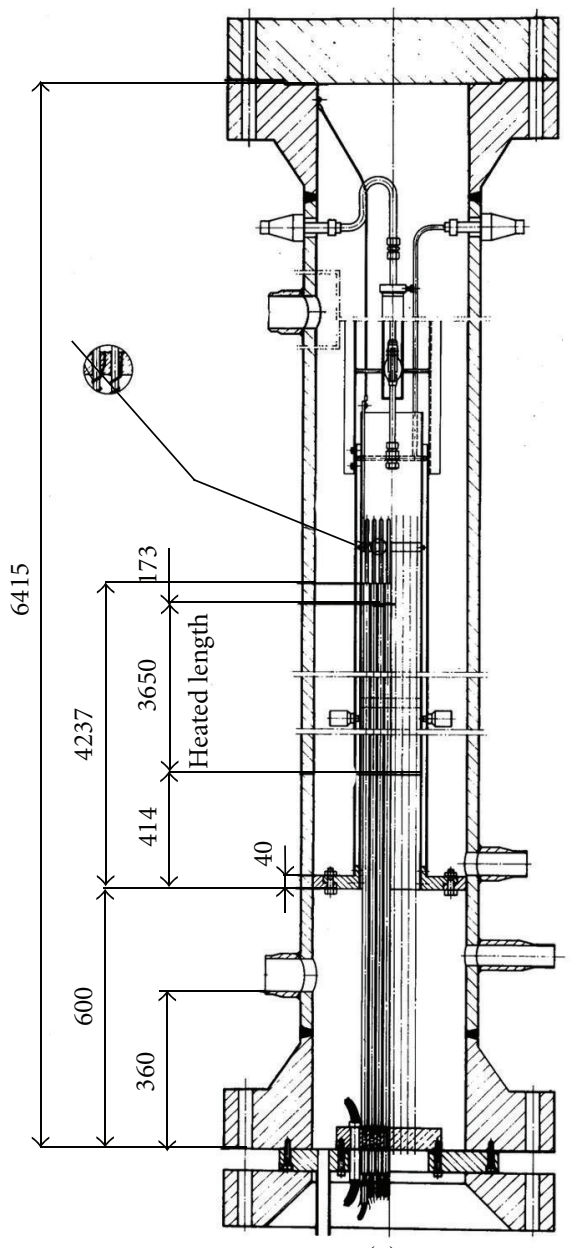

(a)
(a) Spray ring
(b) Space supports
(c) Spray nozzle
(d) Top grid
(e) Outer shroud
(f) Bypass channel outlet

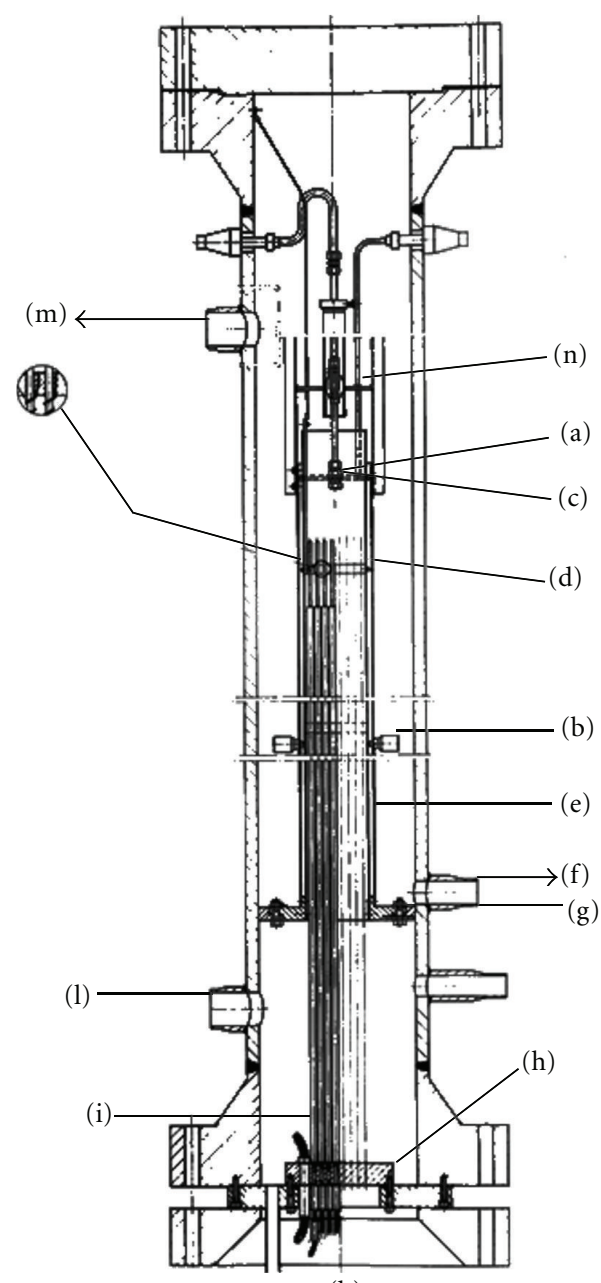

(b)

(g) Flange separating upper and lower plenum

(h) Lower support plate

(i) Graphite seals for TC channels

(1) Internal channel outlet

(m) Steam vent

(n) Inner shroud (canister wall)

Figure 2: Section of the test bundle.

holes with $0.35 \mathrm{~mm}$ diameter drilled in various downward direction angles.

The spray nozzle (Figure 2(c)) for the injection in the bundle is mounted inside the inner shroud, and it ends $170 \mathrm{~mm}$ above the top grid (Figure 2(d)).

The inner channel is made of $\mathrm{Zr}-4$ and has 40 thermocouples mounted on its four sides, placed in pockets drilled from the outside. The outer shroud is made of stainless steel and has 10 thermocouples mounted on two of its four sides.

The 64 heated rods are arranged in the original ASEAATOM spacers. The 7 spacers are mounted at a distance of $561 \mathrm{~mm}$, with one spacer at the lower end of the channel. As the test bundle was dismantled after all the experiments, it was discovered that the spacers had moved during the test series.

The heaters, designed by Watlows Mfg Co, used an Inconel-600 clad and an inner coil $(80 \% \mathrm{Ni}$ and $20 \% \mathrm{Cr})$ embedded in a boron nitride matrix. Five thermocouples were drawn inside the cladding. The heater rod outer diameter is $12.25 \mathrm{~mm}$, except for the three rods in each corner which have an outer diameter of $11.75 \mathrm{~mm}$. A crosssection of the bundle, together with the cross-section of the heater rods, is shown in Figure 3.

The test bundle power supply is provided by two DCconverters coupled in series to achieve the necessary voltage. In order to guarantee the prescribed rod-to-rod power distribution, the heaters are divided in four groups. One of these groups is fed directly by the DC source, while the others are arranged in series with electrical resistances, one for each group. As preresistances, water cooled tubes are used. In this way, the net power supplied to the test bundle is limited to somewhat over $350 \mathrm{~kW}$.

The experiments were run with time-dependent power in the bundle. The power decay curves were chosen to 


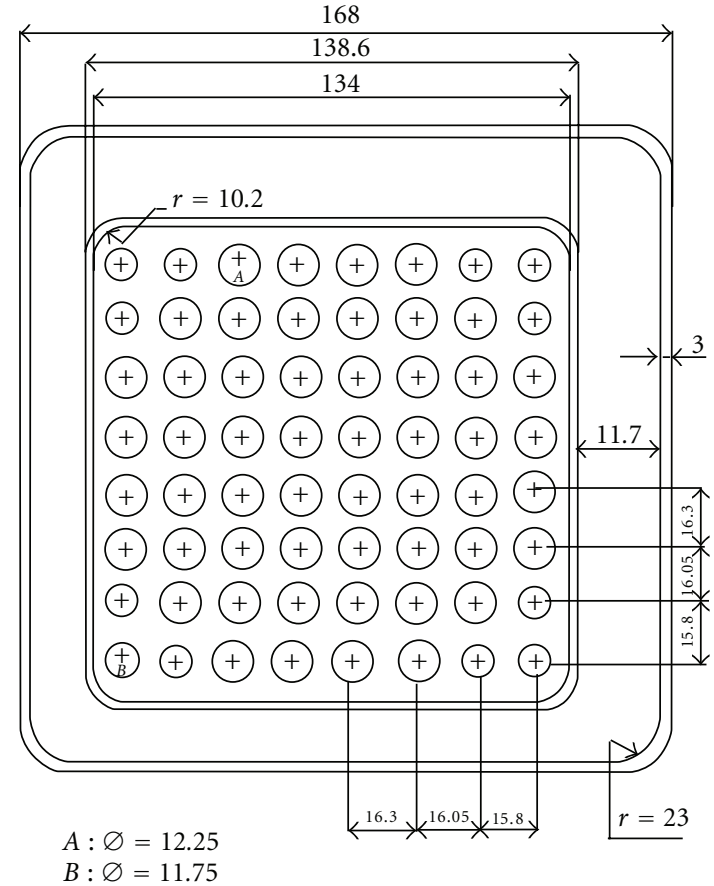

(a)

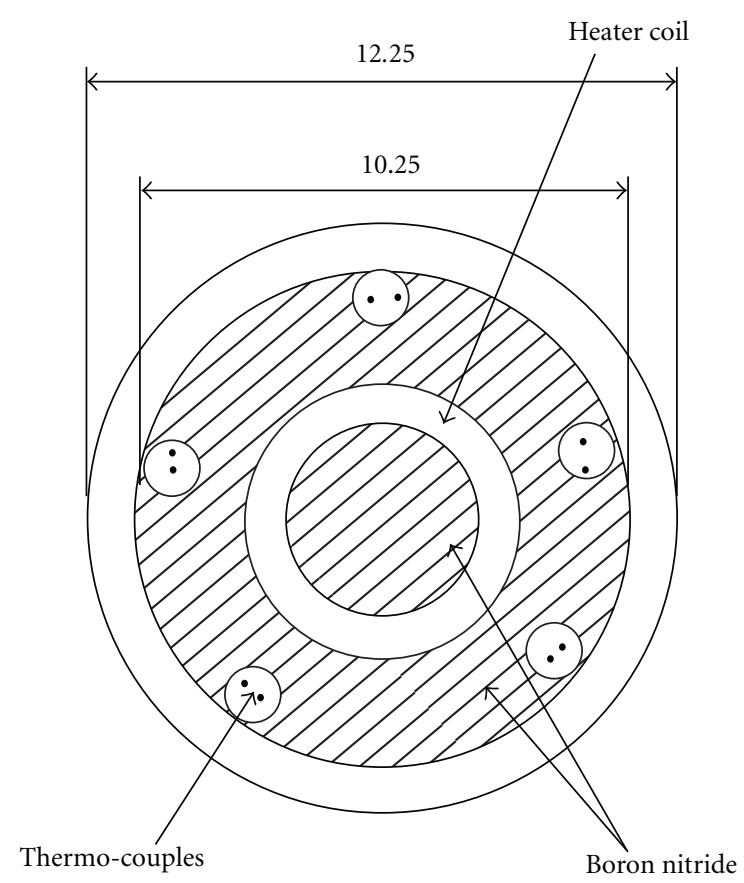

(b)

FIgURE 3: Cross-sections of the bundle and the heater rod.

correspond to the power decay in BWR during the spray cooling injection following a postulated LB-LOCA (large break loss of coolant accident). For a guillotine break on a recirculation line, this phase is calculated to occur approximately 15 seconds after the LOCA. The portion of the power generated by fission products has been calculated according to ANS 1971 decay heat standard plus $20 \%$.

The power inside the channel is delivered in such a way that five different groups of rods can be distinguished. Each group presents a different power peaking factor with respect to the average value and a fixed axial power shape. The internal rod-to-rod power distribution is reported in Figure 4 (highlighting the various groups) together with the axial power profile and the location of the level where the experimental data are available.

2.2. The Test Number 78. Several tests have been carried out in this facility, with different initial conditions and with different configurations of the test loop. In these tests, one or two parameters were varied, while all the others were kept constant. In this paper, only the results of test number 78 will be considered, and compared with the TRACE code calculations.

The test number 78 was conducted on December 10, 1975. The test was started by adjusting the venting valves, the pressure, the spray flow rates, and the water temperature to their prescribed values. After closing the spray injection system, the rods were heated with a low constant power in order to dry all the surfaces (at around saturation temperature). Then, the bundle power was increased according to a predefined power curve until the prescribed initial peak cladding temperature (PCT) at the nominal power was reached. The physical parameters at the beginning of the experiment are listed in Table 1.

The spray system was then activated, and the power was decreased according to the ANS 1971 decay heat standard plus $20 \%$. The water collected in the lower plenum and in the lower part of the bypass channel was drained by two separate lines in short and frequent periods, whenever the void fraction in these volumes fell below fifty percent [3].

The experimental data extracted from test number 78 were the temperatures for each rod group at five different heights. For each rod group and level, a range of temperatures and an average value of all the rods in the group are reported. It is important to note that this is a significant limitation for the correct understanding of the experiment and for the code simulation as it is not possible to identify the temperature evolution of one single rod. Furthermore, at certain levels and for certain groups the gap between the maximum and minimum measured temperature may be more than six hundred Kelvin, even if the cross section of the assembly is symmetrical in the radial direction.

However, the evaluation of an average temperature will be useful for the comparison with the TRACE code, because the TRACE results will be presented as an average temperature of all the rods in a group.

For the purpose of this work, it will be particularly important to verify the capability of the TRACE code to simulate the correct temperature behaviour in the midplane of each rod group (where the temperature reaches its maximum), in order to predict the peak cladding temperature 


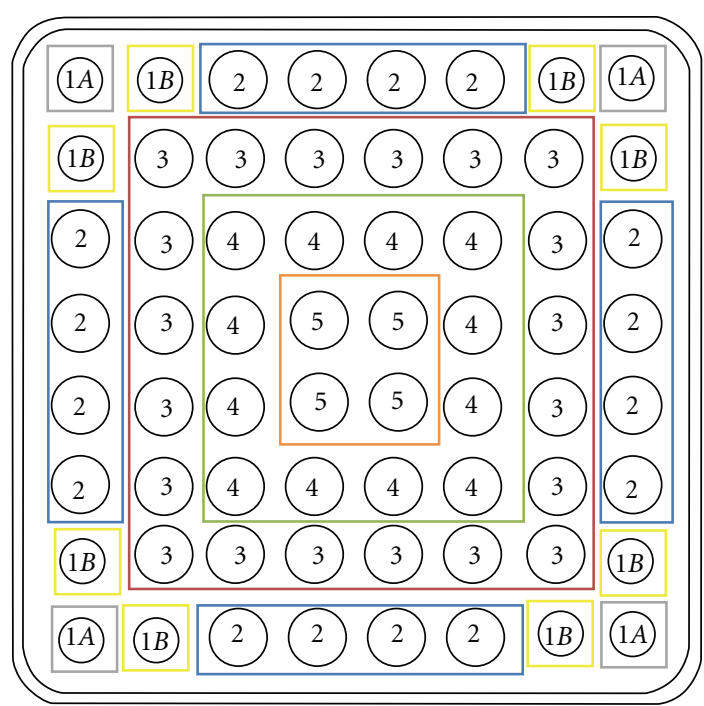

\begin{tabular}{|c|c|c|}
\hline & Rod group & Peak factor \\
\hline- & $1 A$ & 1.2 \\
\hline- & $1 B$ & 1.1 \\
\hline- & 2 & 1.1 \\
\hline- & 3 & 0.92 \\
\hline- & 4 & 0.9 \\
\hline- & 5 & 0.9 \\
\hline
\end{tabular}

(a)

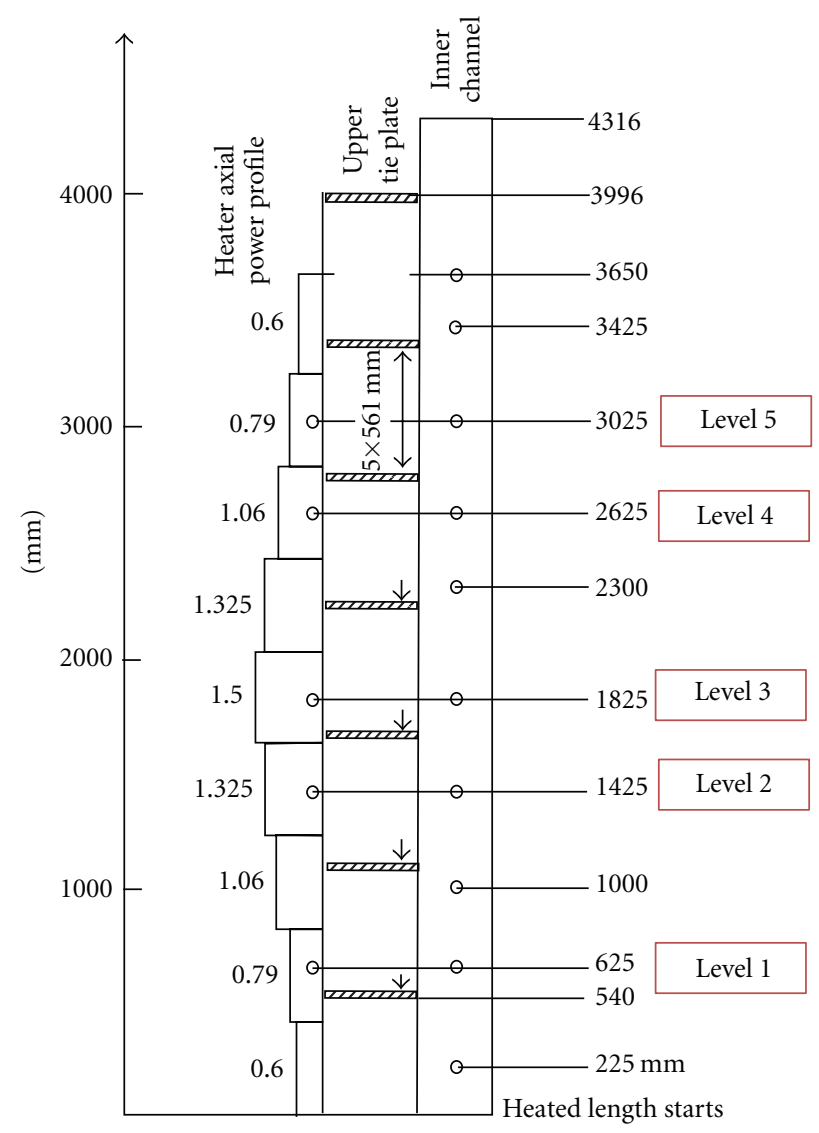

(b)

FIgURE 4: Internal rod- to-rod power distribution (a) and axial power shape (b).

TABLE 1: Test number 78 initial parameters.

\begin{tabular}{lcc}
\hline Parameter & Nominal & Actual \\
\hline Initial bundle power $(\mathrm{kW})$ & 300 & 303 \\
Spray flow rate in the bundle $(\mathrm{kg} / \mathrm{s})$ & 0.12 & 0.12 \\
Fraction of the spray flow rate in the bypass $(\mathrm{kg} / \mathrm{s})$ & $20 \%$ & $20 \%$ \\
Pressure $(\mathrm{MPa})$ & 0.1 & 0.11 \\
Initial peak cladding temperature $\left({ }^{\circ} \mathrm{C}\right)$ & 700 & 736 \\
Spray water temperature $\left({ }^{\circ} \mathrm{C}\right)$ & 60 & 60 \\
Steam venting & Top & Top \\
\hline
\end{tabular}

of the entire assembly, and the position where this value is reached.

\section{Description of the Model}

The simulation of the experiment has been carried out with the U.S. NRC code TRACE, version 5.0 Patch 2. The graphical SNAP interface has then been used to build the nodalization and to prepare model of the GÖTA experiment.

Two different models with different components have been tested. The first one uses two PIPE components to simulate the fuel assembly and the bypass channel, and eight heat structures (HTSTR component) representing the six rod groups (shown in Figure 4), the inner and outer walls.

The second model tested uses the CHAN component for the simulation of the fuel assembly (rods and canister wall) and a PIPE component for the bypass channel. The CHAN component has been designed with the specific purpose of simulating BWR fuel assembly. The nodalization diagrams of both models are shown in Figure 5.

The other elements of the GÖTA facility have been modelled using the same components for both models.

In particular, two FILL components have been used to represent the coolant spray injection system, which operates 


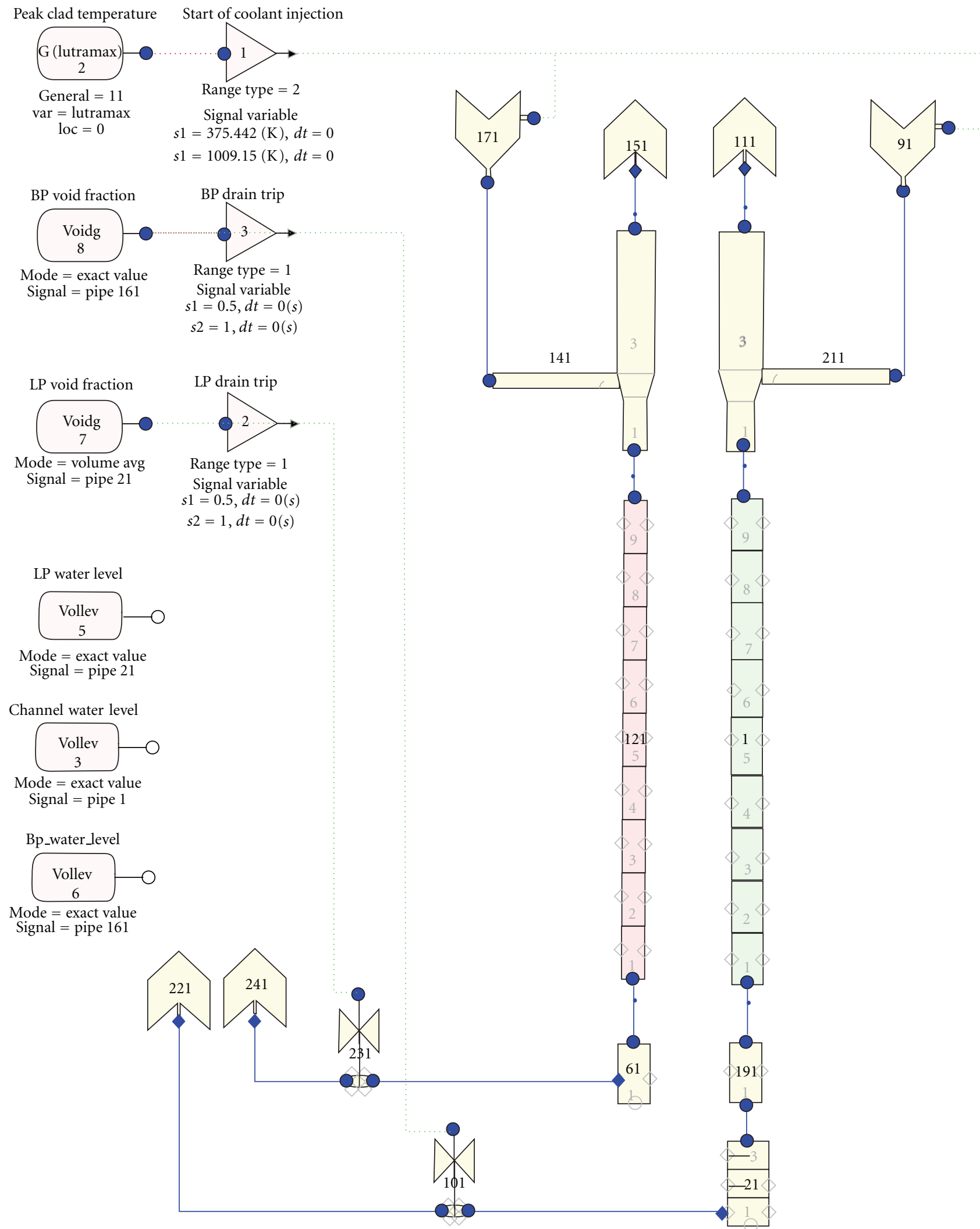

(a)

FIgURe 5: Continued. 
Peak clad temperature Starting of coolant injection
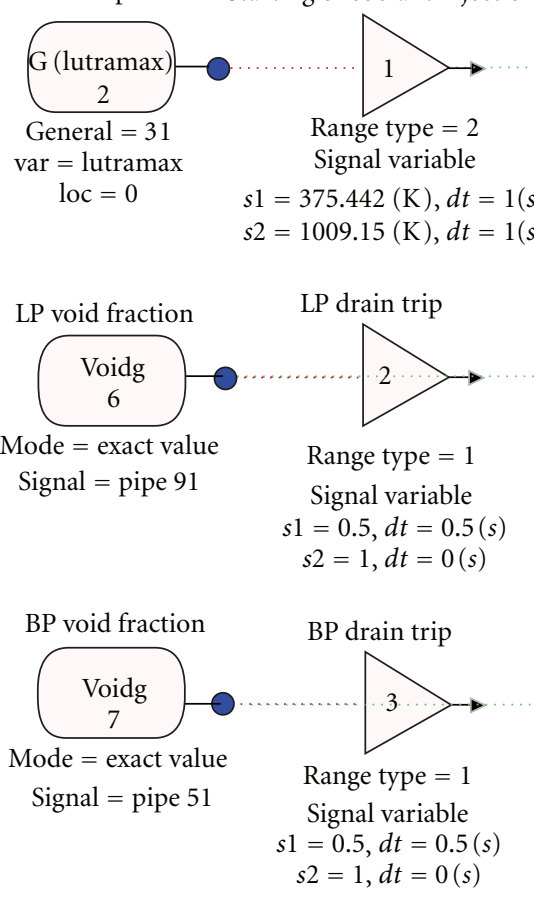

LP_water_level

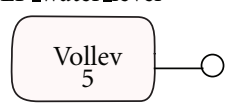

Mode $=$ exact value Signal $=$ pipe 91

Channel_water_level

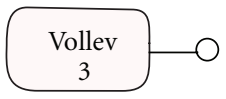

Mode $=$ exact value Signal $=$ channel 1
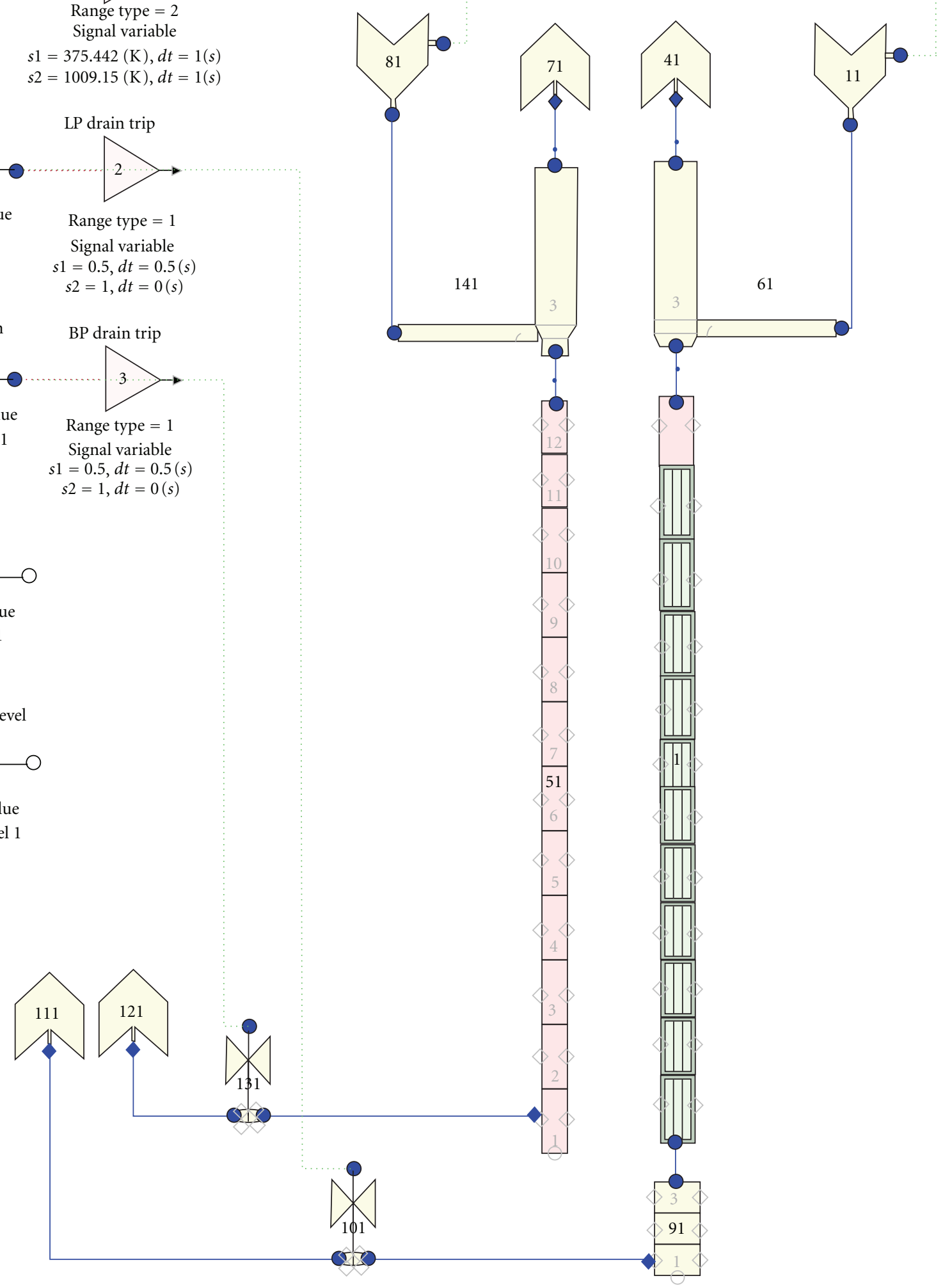

(b)

Figure 5: Nodalization diagrams for PIPE (a) and CHAN (b) models. 
separately for the main channel and for the bypass channel, with two different values of the mass flow rate. The beginning of the spray injection is controlled by a TRIP block, which activates the coolant injection as soon as the peak cladding temperature (measured by another control block) reaches the prescribed value reported in Table 1 .

The upper part of the bundle has been modelled using two BREAK components for the steam vent (one per each channel) and two TEE components that simulate the steam line and the spray cooling line.

A PIPE component has been used to simulate the lower plenum of the bundle. In the "PIPE model," another PIPE component has been used also for the simulation of the lower, unheated part of the channel, while in the "CHAN model," this section of the assembly is included directly in the CHAN component.

The water draining from the bottom of the test vessel has been modelled using two BREAK components. Two VALVE components connect the lower plenum and the lower part of the bypass channel to the BREAK components, respectively.

The opening and closing of the valves is controlled by two TRIP blocks. Each valve is initially closed, and it opens whenever the void fraction in the corresponding section of the test vessel falls below fifty percent.

Other control and signal blocks are added in order to check the behaviour of certain important parameters. In the nodalization diagrams shown in Figure 5, some signal blocks have been added to visualize the collapsed water level in the main channel, in the lower plenum, and in the lower part of the bypass channel.

3.1. Closure Models and Code Options. In order to improve the simulation, several code options and special models have been tested. TRACE code allows great flexibility in the modelling procedure, by allowing including or excluding certain code features by the user.

3.1.1. Fine Mesh Reflood and Axial Heat Conduction. As specified in the TRACE manual, the fine mesh reflood option has to be turned on whenever the calculation results in a significant dryout and heatup of the fuel rods. When this option is active, the HTSTR component has the capability to dynamically add or remove axial nodes during the TRACE calculation. This option produces more accurate prediction of the axial gradient at a quench front moving through a fuel assembly or a fuel rod.

Since this option increases the temperature gradients in the axial direction, the user should consider the activation of the "axial heat conduction" option. If this option is turned off, only heat conduction in the radial direction will be calculated.

The activation of these two options significantly improves the temperature prediction at most of all the axial levels. Turning off these options results in an excessive increase in the temperatures and absence of quench phenomena.

Nevertheless, two important issues related to these features have been found:
(1) increase in the computational time that can vary from few minutes to more than two hours;

(2) very fast quenching in the lower part of the channel (Level 1), which is not confirmed by the experimental data.

3.1.2. Radiation Model. The simulation of radiation heat transfer is very important for the correct representation of the GÖTA experiments. TRACE offers different possibility for the construction of the radiation model, and there are also differences depending on the model (PIPE or CHAN) used. In both cases, the TRACE radiation model requires the definition of all the surfaces involved, and for each surface, the emissivity, the view factors, and the beam lengths with respect to the other surfaces have to be defined.

However, the CHAN component gives a possibility to set the "radiation model" option, which allows the code to evaluate the view factors and beam lengths between all the rods in the channel automatically (through a Monte Carlo simulation). The advantage of this option is the high accuracy in the calculation of all the parameters within the channel. The disadvantage is that this option prevents the user to define a radiation model (RADENC component) that includes the outer surface of the canister wall and the inner face of the bypass channel wall.

This limitation affects the results in a nonnegligible way. Previous investigators [3] found that 20\%-25\% of the heat radiated from the heated rods to the canister's inner side was reradiated from the canister's outer side to the shroud. The lack of canister wall radiation in the TRACE CHAN model results in a higher temperature of the canister wall than measured experimentally.

In order to reduce this effect, a very low value of the emissivity for the inner side of the canister wall has been chosen. In this way, the canister wall absorbs less heat by radiation, keeping its temperature similar to the experimental data.

The values of emissivity used for the simulations have been chosen performing a sensitivity study. It was verified that using 0,3 for the canister wall and 0,67 for the fuel rods lead to a better prediction of the PCT compared to the experimental data. In addition, it has been found that wall emissivity larger than 0,3 prevents the wall to quench resulting in a very high temperature.

On the other hand, no view factors or beam length calculation is provided for the PIPE component, and the user has to define these parameters manually. The radiation model is then implemented by acting directly on the RADENC component. From the point of view of modelling flexibility, this gives the possibility to model the heat exchange between the outer side of the canister wall and the bypass channel wall.

The view factors are input as a matrix, with row index surface connected to column index surface. TRACE requires zero values on the diagonal (which connect the surface to itself) which means that a heat structure cannot "see" itself.

Since the rods have been modelled in a way that a single heat structure represents the entire rod group, it is clear that when the PIPE model is used, it is not possible to simulate 
TABLE 2: View factors from the GÖTA documentation [3].

\begin{tabular}{lcccccc}
\hline & Rod group 1 & Rod group 2 & Rod group 3 & Rod group 4 & Rod group 5 & Canister wall \\
\hline Rod group 1 & 0,1932 & 0,1010 & 0,2033 & 0,0130 & 0,0000 & 0,4895 \\
Rod group 2 & 0,0727 & 0,1899 & 0,3334 & 0,0257 & 0,0024 & 0,3759 \\
Rod group 3 & 0,1170 & 0,2667 & 0,3026 & 0,2498 & 0,0143 & 0,0496 \\
Rod group 4 & 0,0125 & 0,0342 & 0,4164 & 0,3353 & 0,1913 & 0,0103 \\
Rod group 5 & 0,0000 & 0,0096 & 0,0716 & 0,5739 & 0,0018 & 0,0063 \\
Canister wall & 0,4189 & 0,4470 & 0,0736 & 0,0092 & 0,0495 \\
\hline
\end{tabular}

TABLE 3: View factors used in TRACE.

\begin{tabular}{lccccccc}
\hline & Rod group 1A & Rod group 1B & Rod group 2 & Rod group 3 & Rod group 4 & Rod group 5 & Canister wall \\
\hline Rod group 1A & 0,0000 & 0,1932 & 0,1010 & 0,2033 & 0,0130 & 0,0000 & 0,4189 \\
Rod group 1B & 0,1932 & 0,0000 & 0,1010 & 0,2033 & 0,0130 & 0,0000 & 0,4189 \\
Rod group 2 & 0,1010 & 0,1010 & 0,0000 & 0,3334 & 0,0257 & 0,0024 & 0,3759 \\
Rod group 3 & 0,2033 & 0,2033 & 0,3334 & 0,0000 & 0,2498 & 0,0143 & 0,0496 \\
Rod group 4 & 0,0130 & 0,0130 & 0,0257 & 0,2498 & 0,0000 & 0,1913 & 0,0103 \\
Rod group 5 & 0,0000 & 0,0000 & 0,0024 & 0,0143 & 0,1913 & 0,0000 & 0,0063 \\
Canister wall & 0,4189 & 0,4189 & 0,3759 & 0,0496 & 0,0103 & 0,0063 & 0,0000 \\
\hline
\end{tabular}

the heat exchange by radiation between two rods of the same group. Tables 2 and 3 shows the view factors from the test documentation [3] and the values actually used in the TRACE simulation, respectively.

Values in Table 3 are obtained applying the constraints imposed by TRACE to the values reported in Table 2 . In particular, zero values on the diagonal have been set, and the same value of the emissivity for elements $(i, j)$ and $(j, i)$ has to be used.

The deficiencies in the modelling of the view factors with TRACE appears evident from the two tables. For example, observing the rod group 3, it can be noticed that instead of a view factors of 0,3026 TRACE imposes the value of zero. That means that an important part of radiation heat transfer cannot be modelled correctly with TRACE.

Regarding the canister wall, the same issue has been found in the PIPE model as in the CHAN model. The wall emissivity larger than 0,3 prevents the wall to quench resulting in a very high temperature.

3.1.3. CCFL Model. The countercurrent flow limitation is a very important phenomenon from the point of view of the emergency core cooling both in PWR and in BWR. In case of this work, it can occur during the spray injection phase, preventing the cooling of the rods and the wall.

It is a local phenomenon, limiting the liquid flow from the upper part of the channel to the lower region due to the steam flow in the opposite (countercurrent) direction. Any increase in the vapour flux leads to a reduction in the liquid counterflow, until eventually it becomes zero.

In TRACE code, it is possible to evaluate CCFL through three types of correlations: Wallis, Kutateladze, and Bankoff.
The Wallis correlation [4] uses the dimensionless superficial velocity to express the CCFL model, while the Kutateladze correlation [5] expresses the CCFL in terms of Kutateladze number. The Bankoff correlation [6] interpolates the two previous correlations. Equation (1) shows the Wallis, Kutateladze and Bankoff correlations, respectively,

$$
\begin{gathered}
j_{g}^{* 1 / 2}+m_{W} j_{f}^{* 1 / 2}=C_{W}, \\
K_{g}^{1 / 2}+m_{K} K_{f}^{1 / 2}=C_{K}, \\
H_{g}^{1 / 2}+m_{B} H_{f}^{1 / 2}=C_{B},
\end{gathered}
$$

where $m$ and $C$ are the constants determined from the experiment, $j_{i}^{*}, K_{i}$, and $H_{i}^{*}$ are the dimensionless superficial velocity, the Kutateladze number, and the dimensionless flux of phase $i$, and they have the form

$$
\begin{aligned}
& j_{i}^{*}=j_{i}\left[\frac{\rho_{i}}{g d\left(\rho_{f}-\rho_{g}\right)}\right]^{1 / 2}, \\
& K_{i}=j_{i}\left[\frac{\rho_{i}^{2}}{g \sigma\left(\rho_{f}-\rho_{g}\right)}\right]^{1 / 2}, \\
& H_{i}^{*}=j_{i}\left[\frac{\rho_{i}}{g w\left(\rho_{f}-\rho_{g}\right)}\right]^{1 / 2} .
\end{aligned}
$$

In the above equations, $j_{i}$ and $\rho_{i}$ are the superficial velocity and the density of phase $i, d$ is the diameter, $\sigma$ is the 


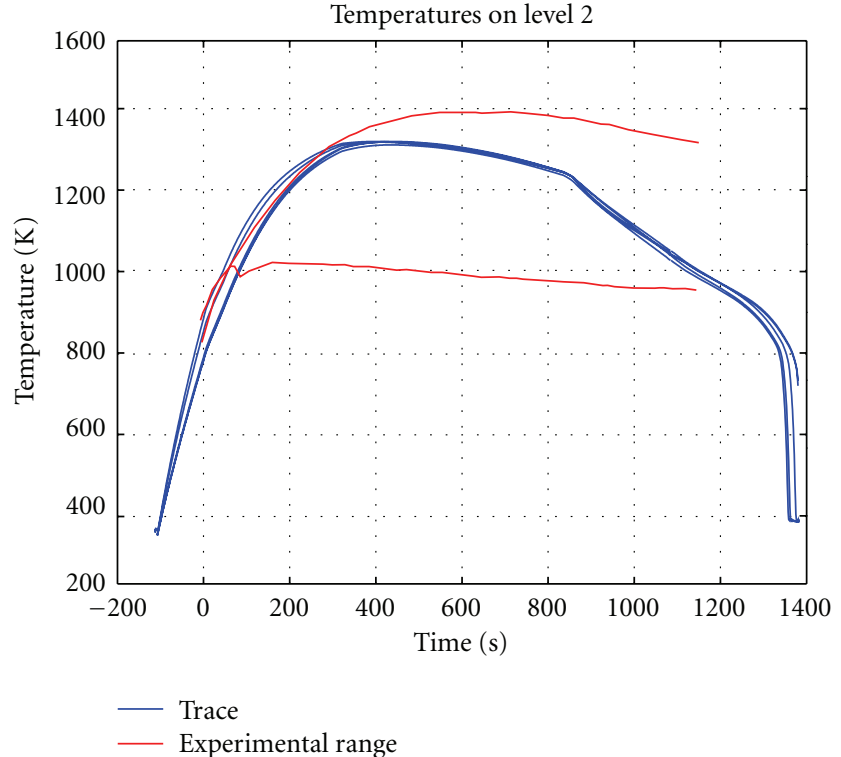

(a)

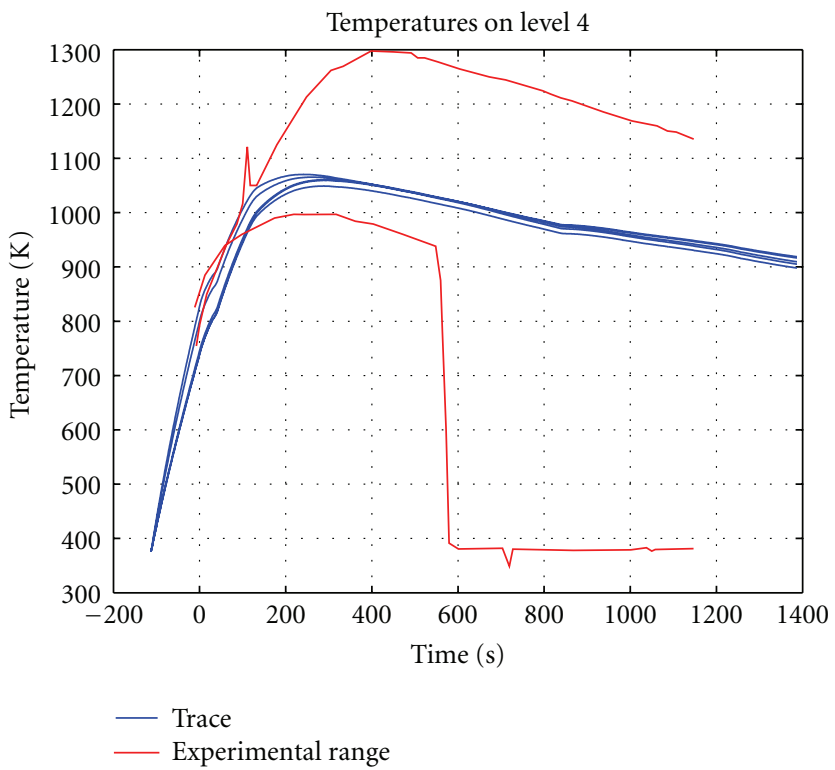

(c)

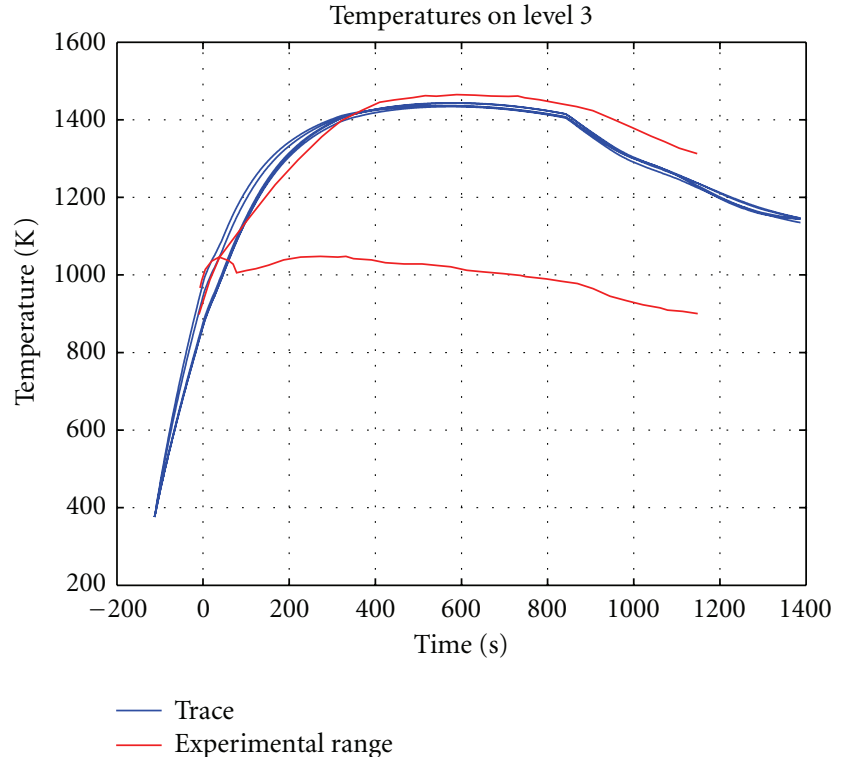

(b)

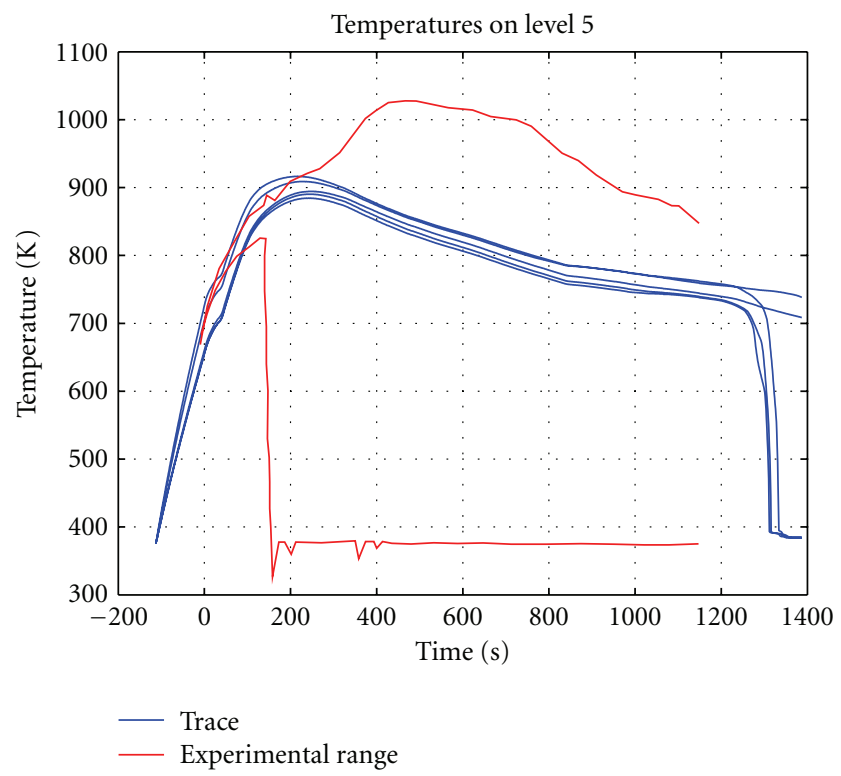

(d)

FIGURE 6: Results of the PIPE model.

surface tension, $g$ is the gravitational constant and $w$ is the interpolative length scale determined from,

$$
\begin{gathered}
w=d^{1-\beta} L_{1}^{\beta}, \quad(0 \leq \beta \leq 1), \\
L_{1}=\left[\frac{\sigma}{g\left(\rho_{f}-\rho_{g}\right)}\right]^{1 / 2}, \\
\beta=\tanh \left(\gamma k_{c} d\right), \\
k_{c}=\frac{2 \pi}{t_{p}},
\end{gathered}
$$

where $L_{1}$ is the Laplace capillarity constant, $\beta$ is the scaling constant between 0 and $1, k_{c}$ is the critical wave number, $\gamma$ is the perforation ratio, and $t_{p}$ is the plate thickness.

Bankoff also developed a correlation for the parameter $C_{B}$ based on the Bond number $\left(L^{*}\right)$,

$$
L^{*}=n \pi d\left[\frac{g\left(\rho_{f}-\rho_{g}\right)}{\sigma}\right]^{1 / 2},
$$

such that,

$$
C_{B}= \begin{cases}1,07+0,00433 L^{*}, & \text { for } L^{*} \leq 200, \\ 2, & \text { for } L^{*}>200,\end{cases}
$$

where $n$ is the number of holes in the tie plate. 


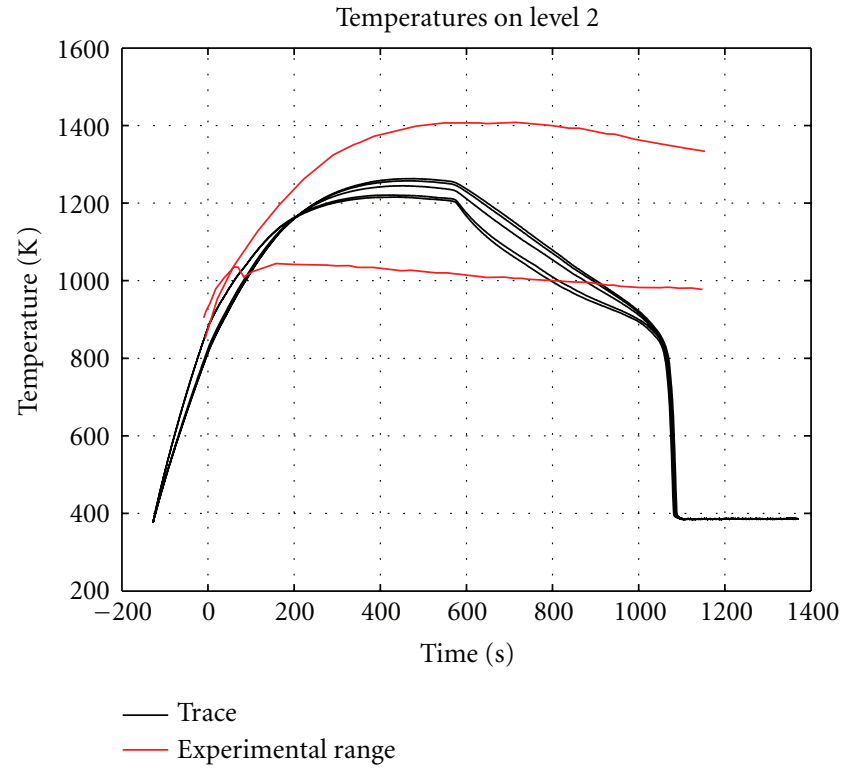

(a)

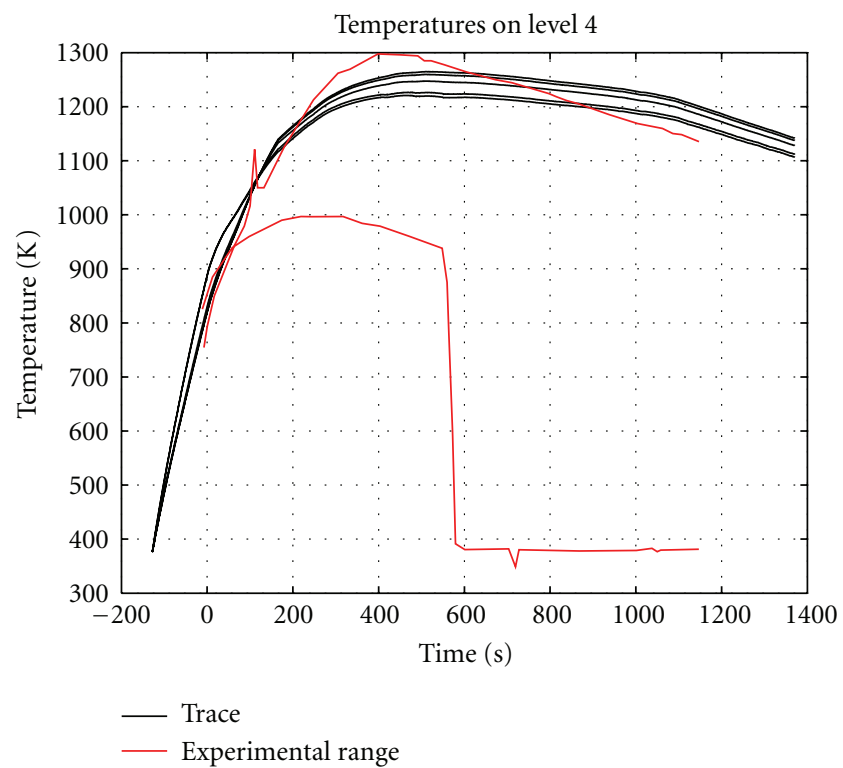

(c)

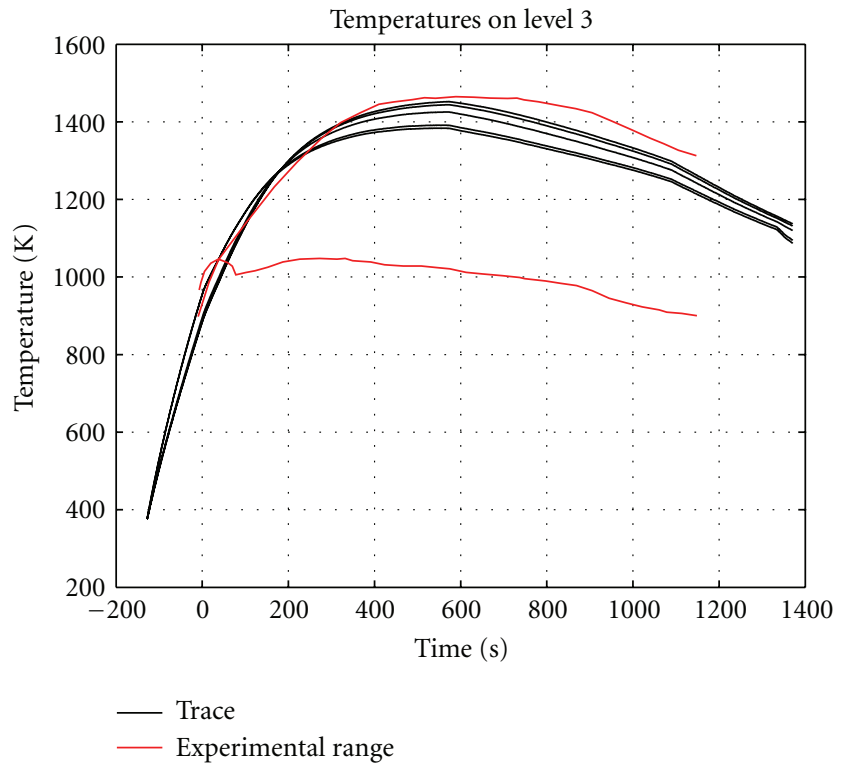

(b)

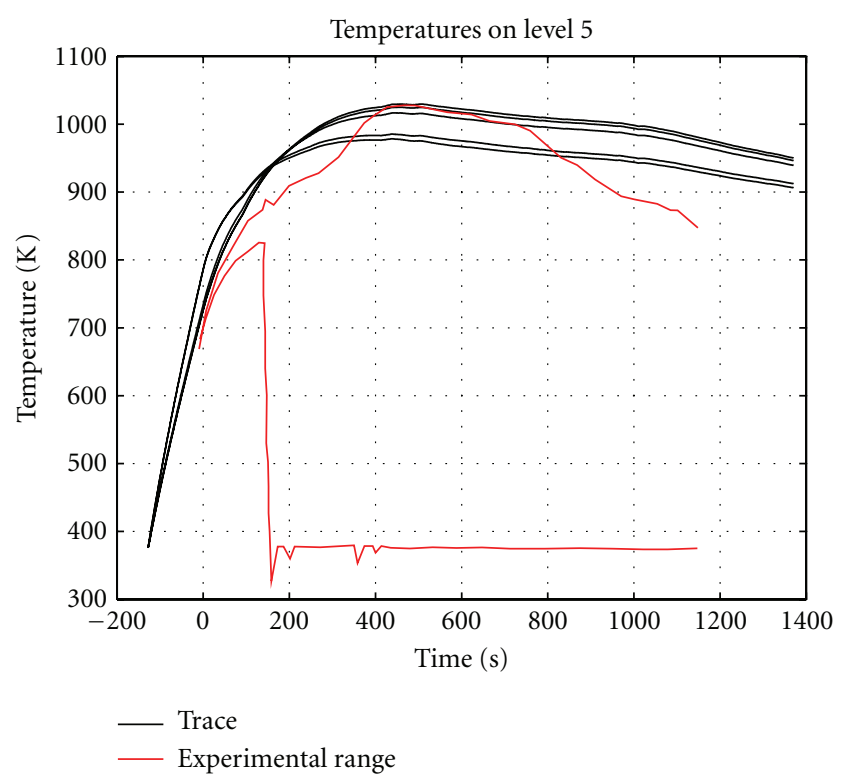

(d)

Figure 7: Results of the CHAN model.

The CCFL model is activated by specifying the location in the component where the phenomenon is expected to occur.

Three parameters have to be set in TRACE in order to define which model the code should use:

(1) the interpolation constant CBETA: the value zero means that the Wallis model will be used, 1 is for the Kutateladze model, and the value between 0 and 1 defines the interpolation constant for the Bankoff model;

(2) the CCFL slope $m$;

(3) the CCFL intercept $C$.
If the Bankoff model is used, the geometrical data of the tie plate has to be defined.

These models have been tested, in particular Bankoff model for the upper tie grid (above the channel) and Wallis and Kutateladze models for the fuel channel. The implementation of the Bankoff model showed no influence on the prediction of the PCT, so it has not been considered for the final calculations. On the contrary, different results have been found with the Wallis and the Kutateladze correlations. Previous studies [7] have shown that the Wallis correlation is preferable if the hydraulic diameter of the pipe is relatively small $(2.5 \mathrm{~mm}$ to $50 \mathrm{~mm})$, so this correlation has been selected to model the CCFL in the GÖTA test bundle. 


\section{Results}

The experimental data used for the comparison are the temperatures measured at different levels in the channel. The data are presented in the test documentation [3] as a range of temperatures where the maximum, the minimum, and an average value are shown for each rod group at each level. In order to simplify the visualization, all the experimental temperatures in each level are shown in one plot, and only the maximum and the minimum values are reported together with all the computed temperatures for that axial level.

The comparison between the calculated and experimental data is shown on Figure 6 for the PIPE model and Figure 7 for the CHAN model. Each line represents the cladding temperature evaluated at each group for one particular axial level.

The results reported in Figure 6 show that the computed temperatures are always within the range of the experimental data. In the upper part of the bundle (Level 4 and 5), the TRACE results follow an average temperature between the maximum and the minimum in the level. In the lower part of the bundle (Level 2 and Level 3), the calculated results are closer to the maximum. In particular, at the Level 3 where the peak cladding temperature is located, TRACE code predicts the evolution of the maximum temperature very well.

It is important to understand the reason for the large difference between the distribution of the calculated and experimental data. In addition to the inaccuracies regarding the modelling of the radiation that have been already described, there is another important issue related to the physics of the experiment.

During the tests in the GÖTA facility, it has been observed that the water injected from the spray in the top of the channel flows downward mainly in the region closer to the canister wall, while the central part of the channel is mainly occupied by the vapour that moves upward. This phenomenon causes a large temperature difference between the rods, because the rods in the peripheral region are cooled significantly more than the inner rods. This effect, together with the fact that the outer rods are facing the canister wall which is at a lower temperature, leads to a large difference between the minimum and the maximum temperature showed in Figures 6 and 7, even if the maximum radial power peaking factor is located in the corner rods (see Figure 4).

It is not possible to simulate this multidimensional phenomenon in PIPE and CHAN component, because of the $1 \mathrm{D}$ approximation used to solve the conservation equations in these components. This inherent limitation of the TRACE code explains the very low temperature differences in the radial direction; the difference between the various rod groups is only due to the radiation model.

The results of the CHAN model (Figure 7) show some differences in the temperature behaviour relative to the PIPE model. The temperatures in the upper part of the bundle (Levels 4 and 5) are slightly overpredicted in the CHAN Model. Even if Levels 4 and 5 maximum cladding temperature is well predicted, the general evolution of the

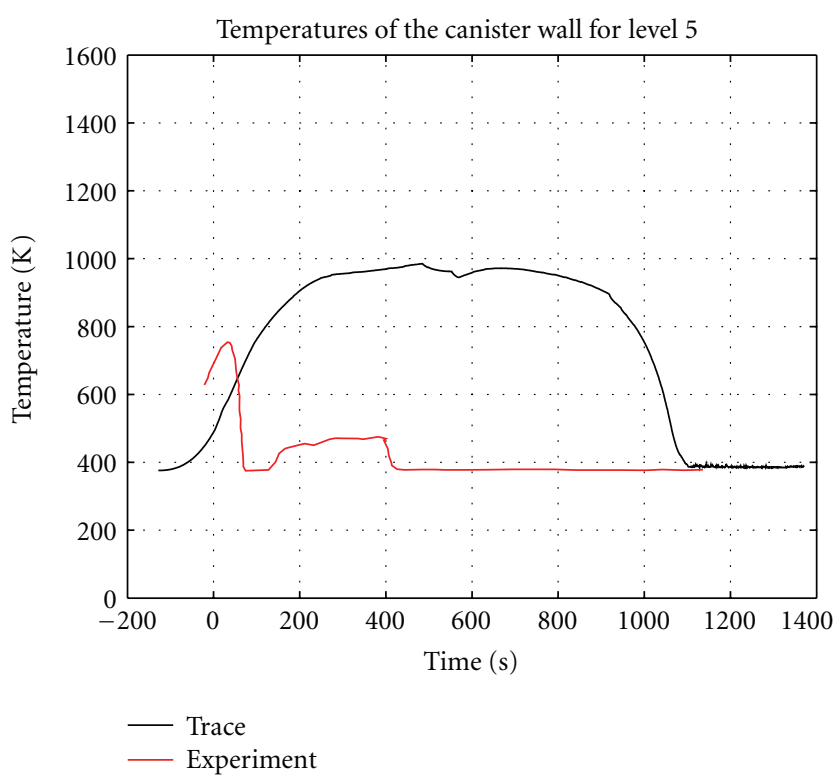

Figure 8: Temperature on the canister wall midplane.

transient shows a much slower temperature decrease with respect to the experiment.

On the other hand, the results in the midplane and in the bottom of the channel (Levels 2 and 3) show that the quenching is predicted earlier than in the experiment, even if the PCT (Level 3) is higher than in the PIPE model.

Similarly as the PIPE Model, the inability of the code to model $2 \mathrm{D}$ phenomena strongly affects the temperature distribution within each level. On the other hand, the identified weakness in the radiation model, present also in the CHAN component, results in an unjustified increase in the temperature of the canister wall mid-plane shown in Figure 8, which is not present in the PIPE model. As has been explained in Section 3.1.2, the code prevents the user to model the heat exchange by radiation from the outer side of the canister wall to the bypass channel, which results in an increase of the wall temperature and a delay in the quench.

Finally, the temperature calculated in the bottom of the channel (Level 1) is reported in Figure 9 in order to show how the fine mesh reflood and axial heat conduction options affect the behaviour of the temperature at the bottom of the channel. A more reasonable solution that fits better the experimental data can be obtained by deactivating those options, but this would cause worse prediction of temperatures on the mid-plane. Since it is more important to predict correctly the peak cladding temperature, we have decided to maintain these options, accepting the error deriving from the code calculation.

\section{Sensitivity and Uncertainty Analysis}

The last part of the experiment analysis consists of the application of a sensitivity and uncertainty analysis. In the past, the licensing has always been done using conservative values for the computations in order to demonstrate the safety margins imposed by the regulations. Nowadays, it is 


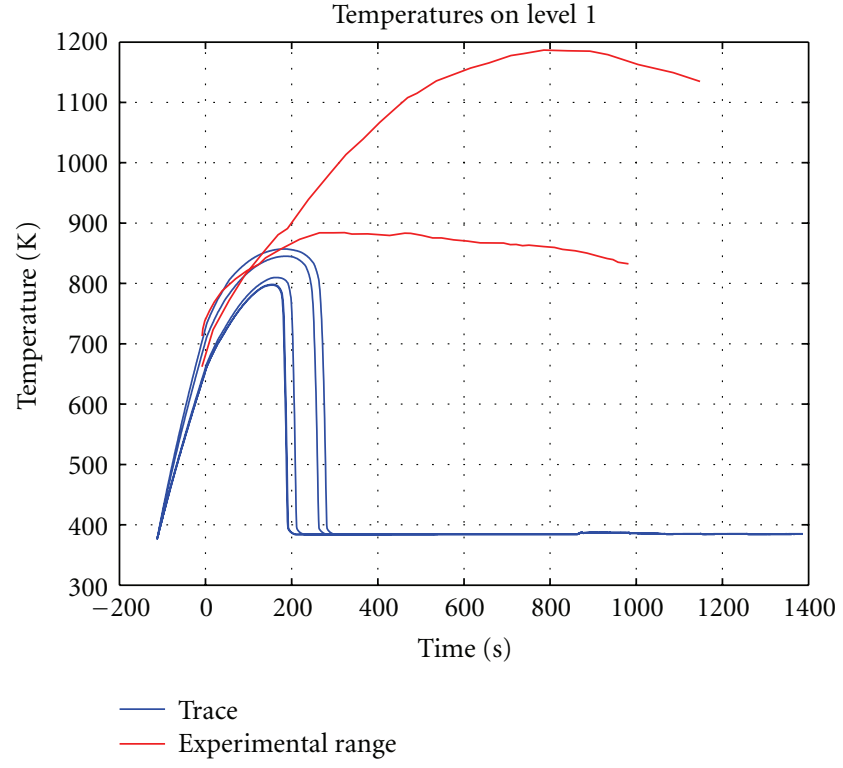

(a)

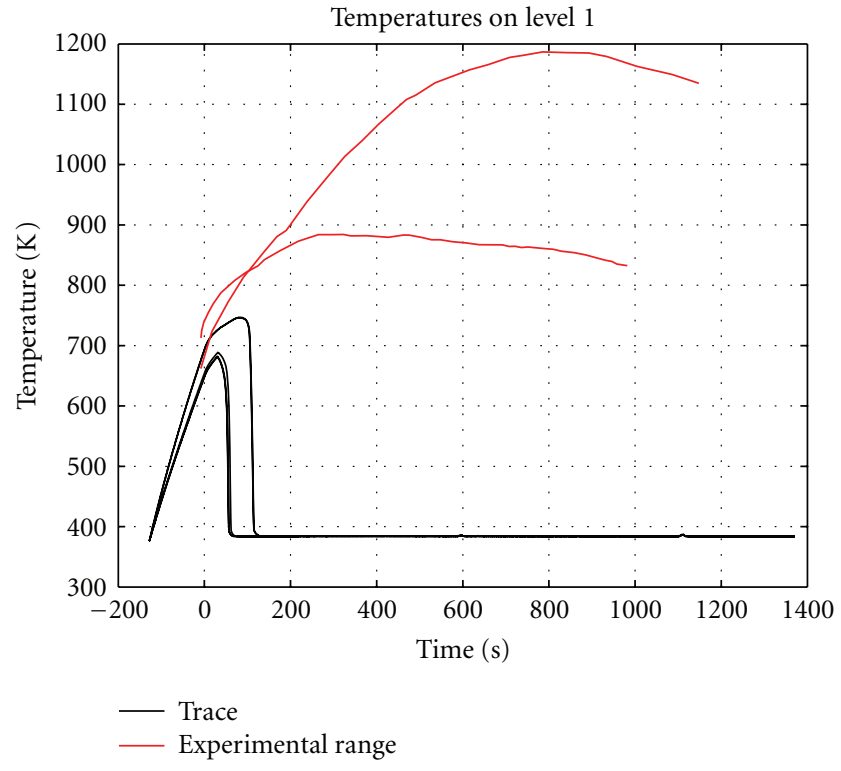

(b)

FIGURE 9: Temperatures computed from the PIPE model (a) and CHAN model (b) at Level 1.

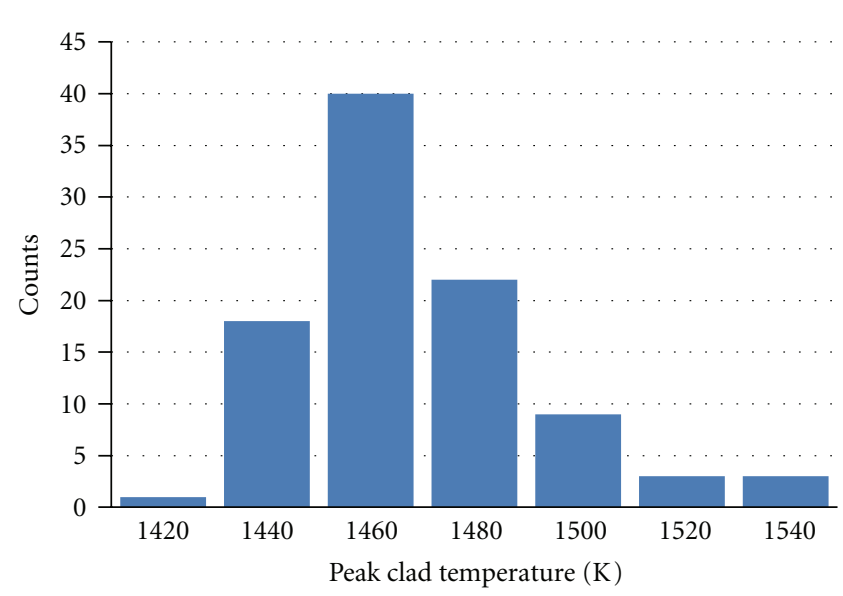

(a)

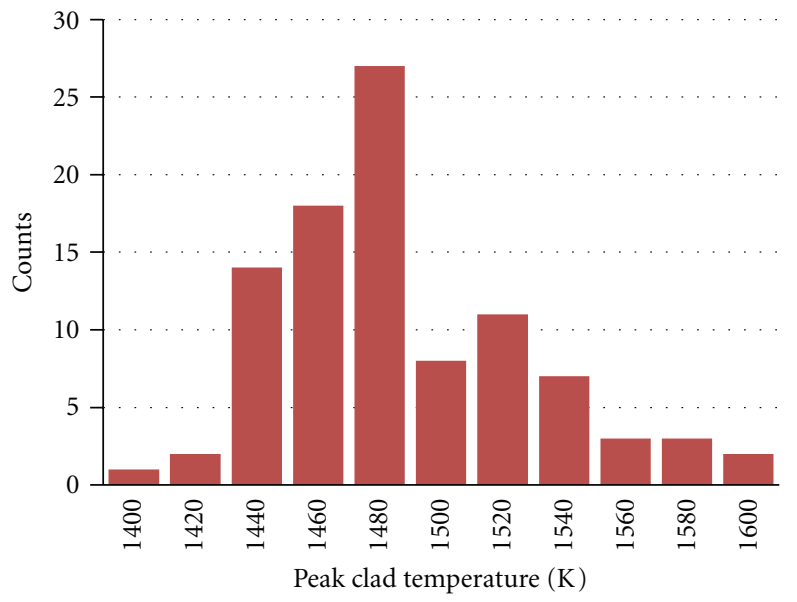

(b)

FIgURe 10: PCT distribution for the PIPE (a) and the CHAN model (b).

possible to estimate certain parameters with best-estimate calculations with the complement uncertainty evaluation, and these calculations can be used for licensing as well. Several methods have been developed for the uncertainty evaluation of system codes. In this work, only propagation of input errors (PIEs) is considered [8].

5.1. Propagation of Input Errors Evaluation. The PIE approach consists of the statistical variation of the input parameters together with their uncertainties, in order to reveal the propagation of errors through the code. Instead of using the input parameters as discrete values, they are varied according to a probability density function (PDF), and a certain number of calculations are performed in order to evaluate distribution and uncertainty of the output parameters.

The PDFs for the various input parameters are derived from the literature and from experts judgment, while the required number of calculations is given by the Wilks formula [9],

$$
1-\left(\frac{\alpha}{100}\right)^{N} \geq \frac{\beta}{100}
$$

which means that $N$ calculations are required to be $\beta \%$ confident that at least $\alpha \%$ of the combined influence of all the characterized uncertainties is below the tolerance limit. 
TABLE 4: Uncertain parameters.

\begin{tabular}{|c|c|c|c|c|}
\hline & Parameter & $1-\sigma$ uncertainty & Type of distribution & Reference \\
\hline & \multicolumn{4}{|c|}{$\mathrm{T} / \mathrm{H}$ initial parameters } \\
\hline 1 & Initial power & $0.75 \%$ & Normal & {$[10$, page 21$]$} \\
\hline 2 & Decay heat power table & $0.75 \%$ & Normal & Own judgment \\
\hline 3 & Water drain temperature & $5 \mathrm{~K}$ & Uniform & Own judgment \\
\hline 4 & Water drain pressure & $0.01 \mathrm{MPa}$ & Uniform & Own judgment \\
\hline 5 & Steam vent temperature & $5 \mathrm{~K}$ & Uniform & Own judgment \\
\hline 6 & Steam vent pressure & $0.5 \%$ & Uniform & Own judgment \\
\hline 7 & Spray system pressure & $5 \%$ & Uniform & Own judgment \\
\hline 8 & Spray system temperature & $0.5 \mathrm{~K}$ & Uniform & Own judgment \\
\hline \multirow[t]{2}{*}{9} & Spray system mass flow & $0.5 \%$ & Uniform & [10, page 21$]$ \\
\hline & \multicolumn{4}{|c|}{ Vessel-related parameters } \\
\hline 10 & Tee roughness & $30 \%$ & Normal $^{(a)}$ & [10, page 3.32] \\
\hline 11 & Bundle wall roughness & $30 \%$ & Normal $^{(a)}$ & {$[11$, page 3.32$]$} \\
\hline 12 & Bypass channel wall roughness & $30 \%$ & Normal $^{(a)}$ & [11, page 3.32] \\
\hline 13 & Length of main channel & $1 \mathrm{~mm}$ & Uniform & Own judgment \\
\hline 14 & Length of the bypass channel & $1 \mathrm{~mm}$ & Uniform & Own judgment \\
\hline 15 & Length of the main channel tee & $1 \mathrm{~mm}$ & Uniform & Own judgment \\
\hline \multirow[t]{2}{*}{16} & Length of the bypass tee & $1 \mathrm{~mm}$ & Uniform & Own judgment \\
\hline & \multicolumn{4}{|c|}{ Bundle-related parameters } \\
\hline 17 & Bundle flow area & $0.5 \%$ & Uniform & Own judgment \\
\hline 18 & Bundle hydraulic diameter & $0.5 \%$ & Uniform & Own judgment \\
\hline 19 & Bypass channel Flow Area & $0.5 \%$ & Uniform & Own judgment \\
\hline 20 & Bypass hydraulic diameter & $0.5 \%$ & Uniform & Own judgment \\
\hline 21 & Spacers friction & $5 \%$ & Uniform & [8, page 35] \\
\hline 22 & Rod emissivity & $15 \%$ & Uniform & Own judgment \\
\hline 23 & Bundle wall emissivity & $15 \%$ & Uniform & Own judgment \\
\hline 24 & CCFL slope & $10 \%$ & Uniform & Own judgment \\
\hline \multirow[t]{2}{*}{25} & CCFL constant & $10 \%$ & Uniform & Own judgment \\
\hline & \multicolumn{4}{|c|}{ Timing } \\
\hline 26 & Spray injection trip & $1 \mathrm{~s}$ & Uniform & Own judgment \\
\hline 27 & Drain valve trip delay & $0.5 \mathrm{~s}$ & Uniform & Own judgment \\
\hline
\end{tabular}

${ }^{\mathrm{a}}$ The distribution was approximated with normal.

The formula for the two-sided statistical tolerance intervals is given as

$$
1-\left(\frac{\alpha}{100}\right)^{N}-N\left[1-\left(\frac{\alpha}{100}\right)\right]\left(\frac{\alpha}{100}\right)^{N-1} \geq \frac{\beta}{100},
$$

where $\alpha$ and $\beta$ have the same meaning as the previous equation. The level of coverage/confidence used for the uncertainty calculation on the TRACE models of the GÖTA is $95 \% / 95 \%$. The two-sided formula has been used which means that 93 calculations are required.

Table 4 shows all the input parameters that have been taken into account in this study. The references are reported for parameters found in the literature; while for those which no literature has been found, the PDF is based on our own judgment.

No rigorous methodology is used to select the parameters listed in Table 4. The considered parameters, as well as their uncertainties, are rather illustrative than precise. For this reason, the uncertainty study reported here should be considered as an example of uncertainty calculation used to demonstrate the feasibility of this procedure.

The PIE method has been applied for both the PIPE and the CHAN models, using exactly the same uncertainty parameters (Table 4) and the same number of calculations (93). The output parameter chosen for the PIE evaluation is the PCT, and the distribution of this parameters obtained from the PIE calculations is reported for both models in Figure 10.

The results of the uncertainty evaluation of the PIPE model show that the spread of the output parameter (PCT) can be approximated with the normal distribution, and the peak of the distribution is located on the interval 1440$1460 \mathrm{~K}$, which is in a good agreement with the experimental data.

The distribution of the CHAN model output parameter (PCT) differs in the location of the peak and the distribution. The peak of the PCT distribution is located on the interval 1460-1480 K, it has larger spread (standard deviation), and 


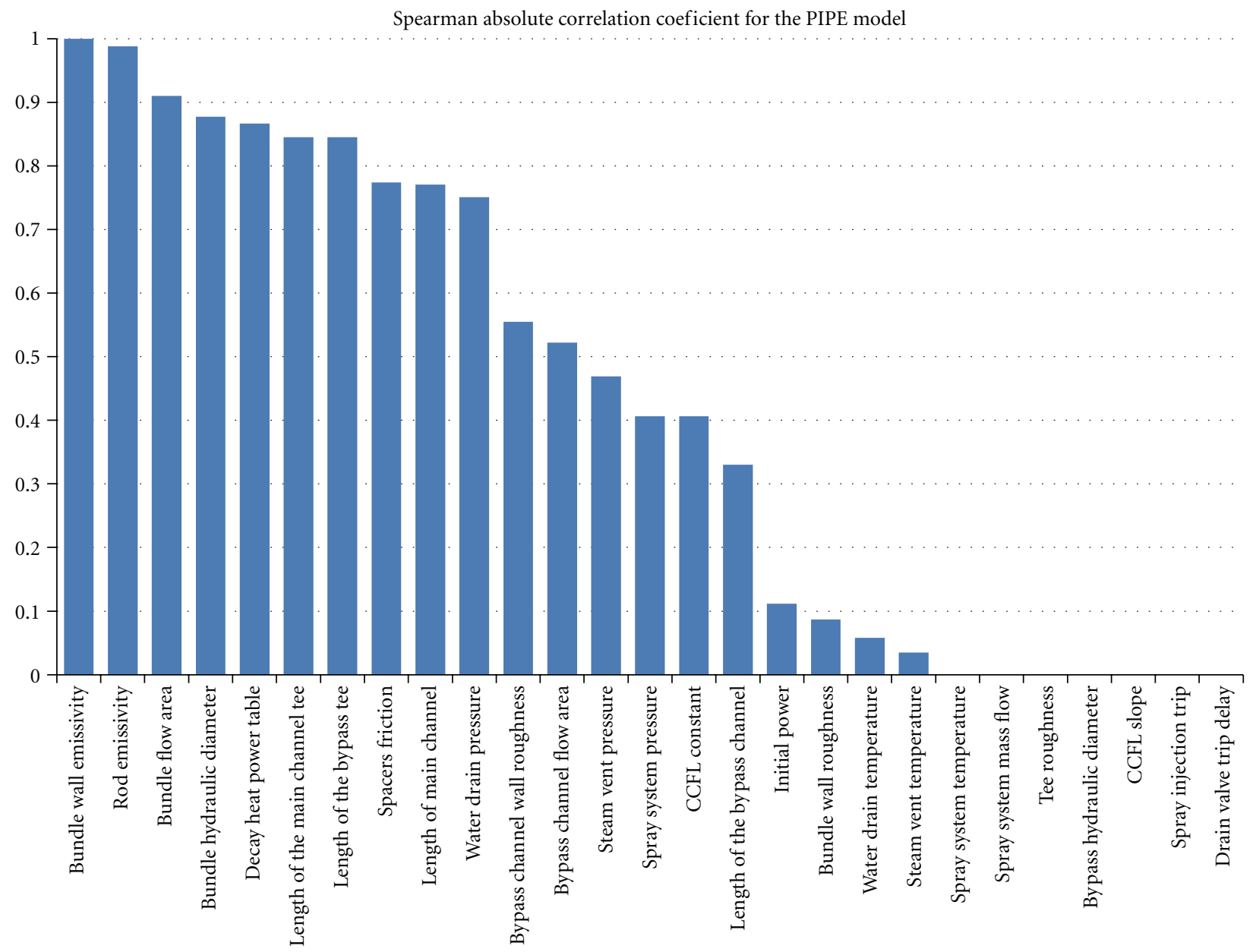

FIgURe 11: Absolute Spearman correlation coefficient for the PCT for the PIPE model.

it does not fit the normal distribution. This implies that the CHAN model results have larger uncertainty than the PIPE model results.

5.2. Sensitivity Analysis. A sensitivity study has been performed on all the parameters in Table 4, in order to define the most influential input parameter on the figure of merit (PCT).

The Spearman correlation is used to obtain the correlation coefficient between the input parameter and the output. This coefficient provides a quantitative measure of effect the input parameter has on the output figure of merit (PCT) [8].

If $n$ variation of the parameters is done, the $n$ raw scores $X_{i}$ and $Y_{i}$ are converted to ranks $x_{i}$ and $y_{i}$, and the differences $d_{i}=x_{i}-y_{i}$ between the ranks of each observation on the two variables are calculated. If there are no tied ranks, the Spearman correlation coefficient is defined as follows [12]:

$$
\rho=1-\frac{6 \sum d_{i}^{2}}{n\left(n^{2}-1\right)} .
$$

In Figures 11 and 12 the absolute value of the Spearman correlation coefficient is reported for each parameter for PIPE and CHAN models, respectively.
The results from the PIPE model show that the two most influential parameters are the rod and the wall emissivity. This confirms that the radiation heat transfer plays a very important role in the cooling of the bundle, especially the interactions between the rods and the canister wall. Other important parameters are the one related to the geometry of the channel, that is, the flow area and the hydraulic diameter. These parameters influence the mass flow rate of water and steam through the channel which determines the "coolability" of the rods.

The results from the CHAN model show that the most influential parameter is the CCFL constant. The CHAN model is much more sensitive to the CCFL phenomenon than the PIPE model. Nevertheless, the Spearman correlation coefficient for the bundle wall emissivity shows that radiation model still plays a very important role in the evolution of the transient.

These results should be considered keeping in mind that the CHAN model overestimates the temperature at the top of the bundle, and it has been identified that the CCFL model has a significant contribution in this overestimation.

It is also important to note that the geometrical parameters that played a nonnegligible role in the PIPE model are 


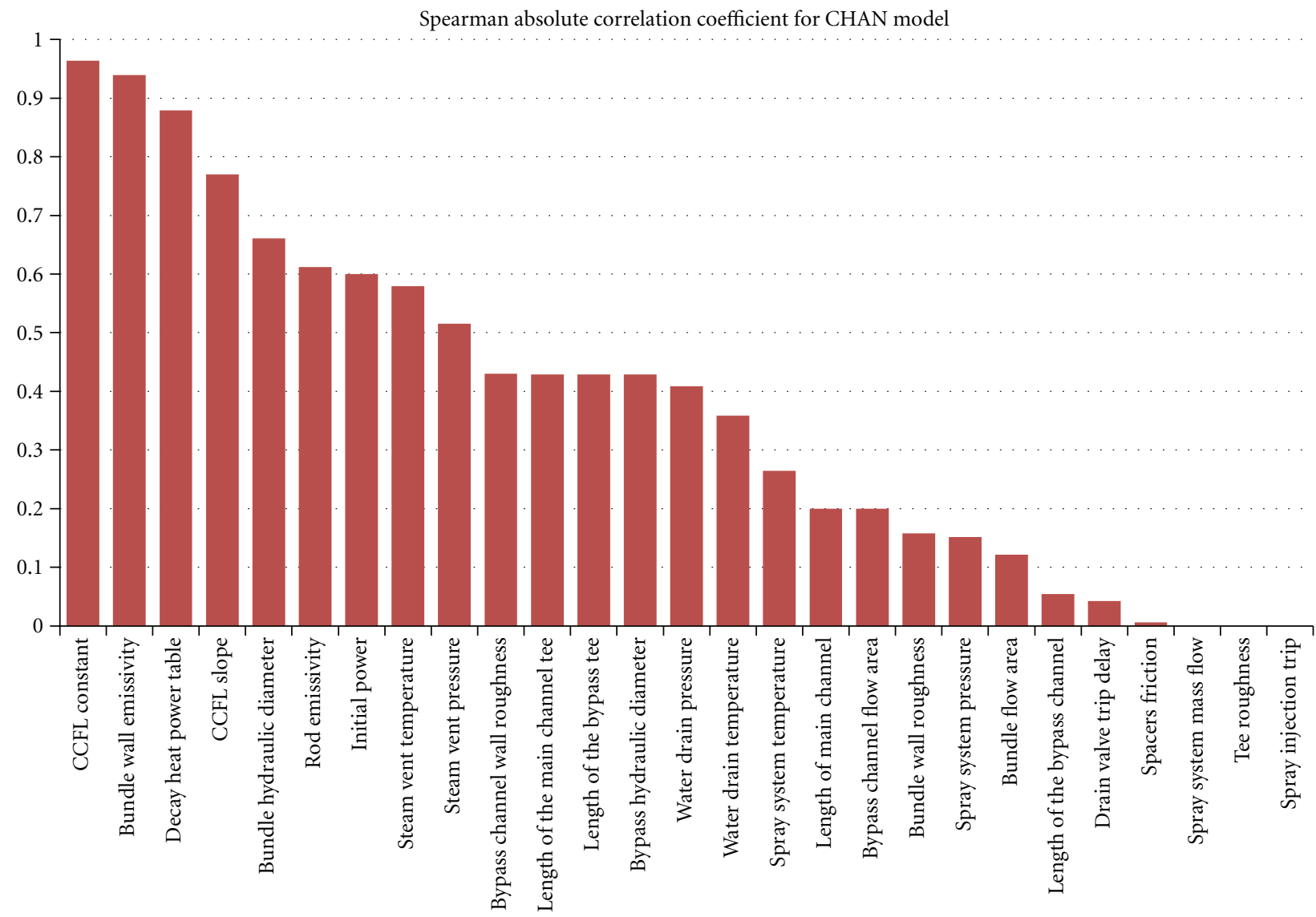

FIgURE 12: Absolute Spearman correlation coefficients for the PCT for the CHAN model.

less important for the CHAN model, while the boundary conditions, that is, pressure and temperature at the FILL and BREAK components, affect more the results of the CHAN model.

\section{Conclusion}

In this paper, the results derived from two different TRACE models of the GÖTA test facility have been analysed and compared. An uncertainty study has been performed, and the most influential parameters have been determined.

First, the results clearly show that the inability of the PIPE and CHAN components to model 2D phenomena does not prevent the code from a reasonable prediction of the PCT and its evolution in time, which is very important from the safety point of view. Only the trend of the best-estimate results for the PCT is captured.

It was found that for the considered experiment, the PIPE model provides a slightly better prediction of the PCT than the CHAN model. However, both models predict an incorrect behaviour in the lower part of the channel (Level 1 ), where the activation of the axial heat conduction option results in a strong underestimation of the temperatures for all the rod groups.

These results suggest that for the simulation of such kind of facility, it is better to use a more flexible component that allows the user to set more input parameters. For instance, the PIPE component has a possibility to create the fuel heat structures separately and to set different value of emissivity in each one of them. This is not possible with the CHAN component, since only one value of emissivity is used for all the rods. Moreover, the possibility to set own value of the view factors represents additional degree of freedom for the PIPE component.

Finally, the results of the uncertainty calculations show that the PIPE model has a smaller uncertainty in the figure of merit (PCT). In fact, Figure 10 (a) shows how most of the computed PCTs are in the same interval as the experimental data (1440-1460 K). On the other hand, it can be noticed that the CHAN model overestimates the PCT.

On the basis of the uncertainty analysis performed, the most influential parameters for the PIPE model are the wall and the rod emissivity. These results highlight the importance of radiation heat transfer in a fuel assembly when the cladding temperature in the core is high (i.e., close, or above $1000 \mathrm{~K}$ ). These results also emphasize the need of improving the radiation model in TRACE both in the CHAN and PIPE components.

On the other hand, the most influential parameter for the CHAN models is the CCFL correlation constant. This explains the overprediction of the temperature on the top of 
the bundle, which is due to an overestimation in the CCFL phenomenon.

\section{Abbreviations}

1-D, 2-D: One dimensional, two dimensional

ANS: $\quad$ American Nuclear Society

BWR: Boiling water reactor

CCFL: Counter current flow limiting

ITF: Integral test facility

LB-LOCA: Large break loss of coolant accident

NPP: $\quad$ Nuclear power plants

PCT: $\quad$ Peak cladding temperature

PDF: $\quad$ Probability density function

PIE: $\quad$ Propagation of input errors

PWR: $\quad$ Pressurized water reactor

SETF: $\quad$ Separate effect tests facility

SNAP: $\quad$ Symbolic nuclear analysis package

THSC: Thermal-hydraulic system codes

TRACE: TRAC/RELAP Advanced Computational Engine

U.S. NRC: United States Nuclear Regulatory Commission.

\section{References}

[1] F. D'Auria, A. Bousbia-Salah, A. Petruzzi, and A. Del Nevo, "State of the art in using best calculation tools in nuclear technology," Nuclear Engineering and Technology, vol. 38, no. $1,2006$.

[2] S. O. Eriksson, R. Harju, and R. Pettersson, "BWR emergency core cooling investigations: spray cooling heat transfer experiment in a full scale BWR bundle mock-up," DSF Project No 1-STUDSVIK/E4-78/64, Studsvik, 1978.

[3] D. L. Caraher and Ö. Rosdahl, "Assessment of RELAP5/MOD2 Radiation and Quench Model Using GÖTA Spray Cooling Test 78 Data," SKY Project 13.3-917/84 - STUDSVINK/NP-87/43, Studsvik, 1987.

[4] G. B. Wallis, One Dimensional Two-Phase Flow, McGraw-Hill, New York, NY, USA, 1969.

[5] S. S. Kutateladze, "A hydrodynamic theory of changes in the boiling process under free convection," Izvestia Akademii Nauk, USSR, Otdelenie Tekhnicheski Nauk, vol. 8, p. 529, 1951.

[6] S. G. Bankoff, R. S. Tankin, M. C. Yuen, and C. L. Hsieh, "Countercurrent flow of air/water and steam/water through a horizontal perforated plate," International Journal of Heat and Mass Transfer, vol. 24, no. 8, pp. 1381-1395, 1981.

[7] Y. H. Cheng, J. Rwang, C. Shih, and H. T. Lin, "A study of steam-water countercurrent flow model in TRACE code," in Proceedings of the 17th International Conference on Nuclear Engineering, Brussels, Belgium, 2009.

[8] I. Gajev, Sensitivity and uncertainty analysis of BWR stability, Licentiate Thesis in Energy Technology, KTH Engineering Sciences, Stockholm, Sweden, 2010.

[9] H. Glaser, "GRS method for uncertainty and sensitivity evaluation of code results and application," Science and Technology of Nuclear Installation, vol. 2008, Article ID 798901, 7 pages, 2008.

[10] B. Neykov, F. Aydogan, L. Hochreiter et al., "OECD-NEA/USNRC/NUPEC BWR Full-size Fine-Mesh Bundle Test (BFBT) Benchmark," Volume I: Specifications, OECD 2006, NEA No. 6212, NEA/NSC/DOC, 2005.
[11] T. Wickett, F. D'Auria, and H. Glaeser, "Report of the uncertainty method study for advanced best estimate thermalhydraulic codes applications," page 14, Vol. I OECD/CSNI Report NEA/CSNI R (97) 35, Paris, France, 1998.

[12] J. L. Mayers and A. D. Well, Research Design and Statistical Analysis, Lawrence Erlbaum, 2002. 

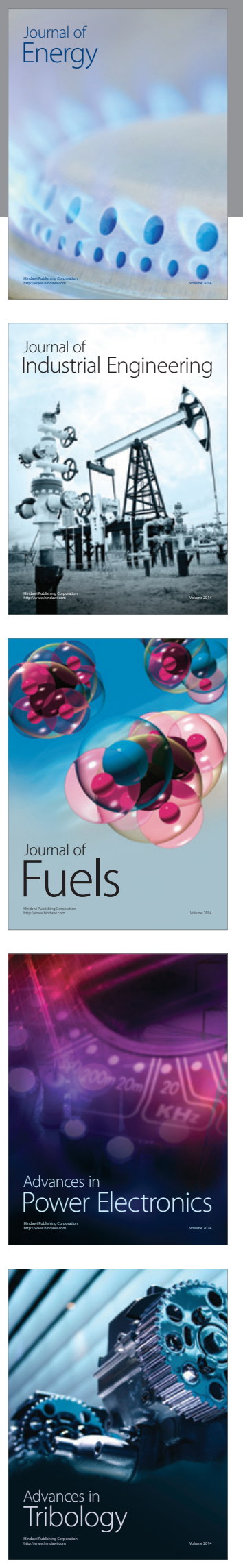
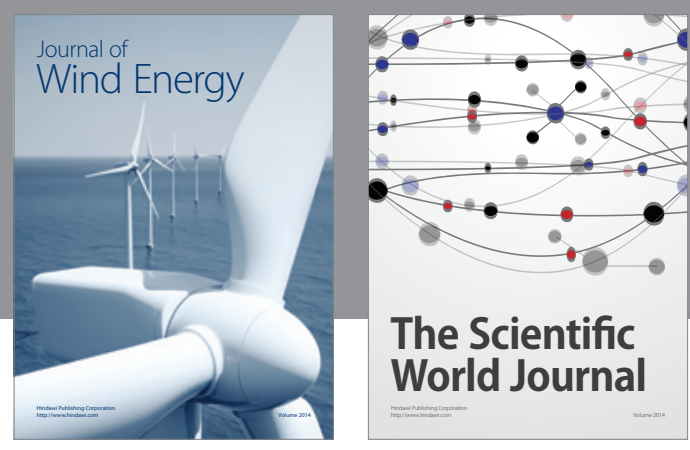

The Scientific World Journal

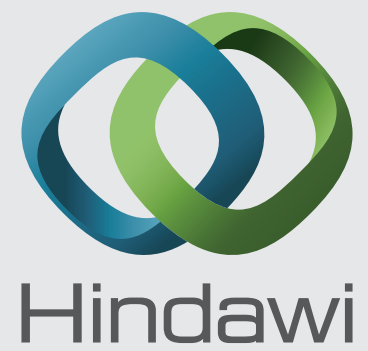

Submit your manuscripts at http://www.hindawi.com
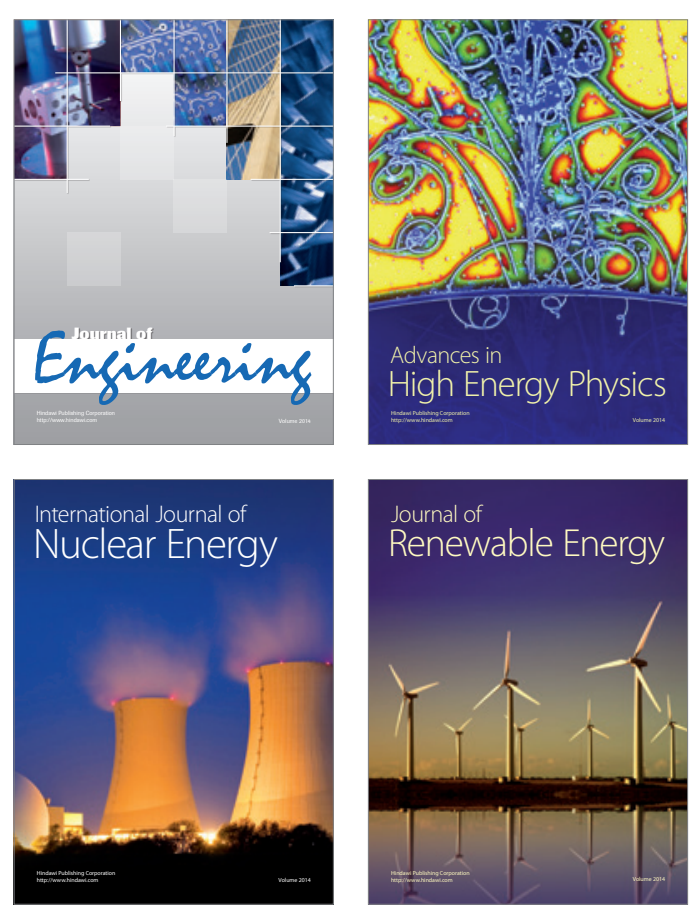

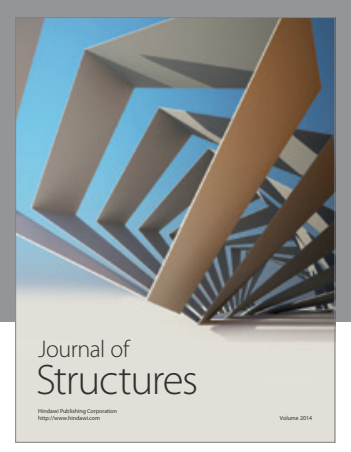

Rotating
Mechinery
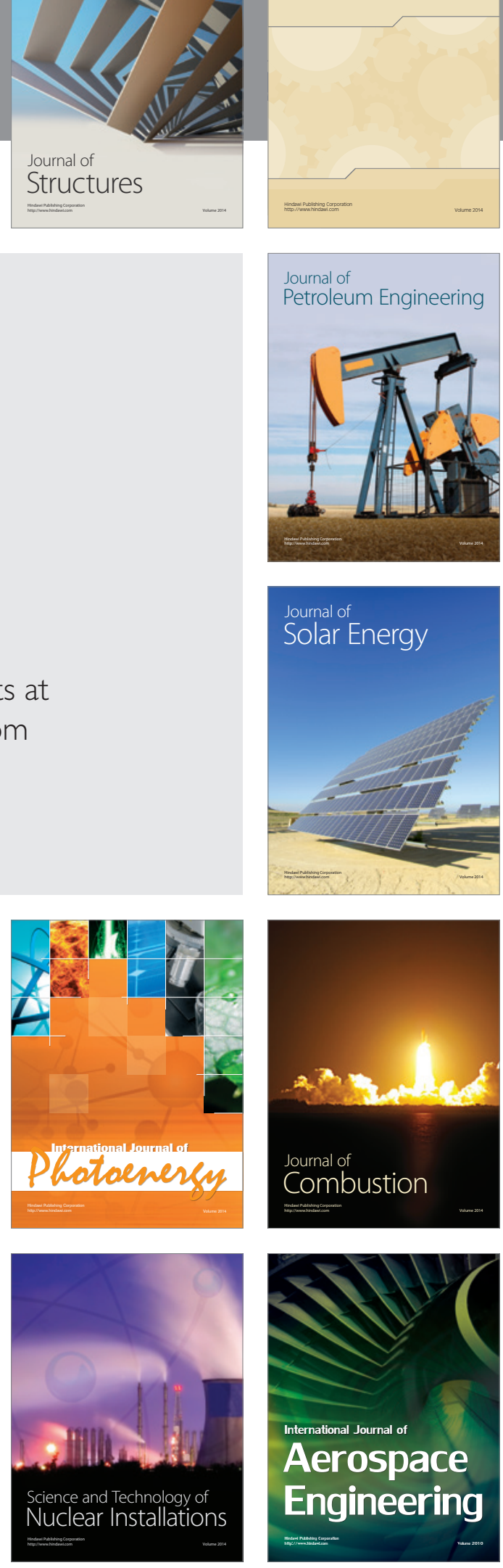